\title{
Cambios económicos, movilidad residencial y gentrificación en la ciudad de Valencia (2014-2017)
}

\author{
Julia Salom Carrasco \\ María Dolores Pitarch Garrido \\ Universitat de València. Instituto Interuniversitario de Desarrollo Local \\ julia.salom@uv.es \\ maria.pitarch@uv.es
}

\section{Resumen}

El objetivo de este artículo es identificar los cambios recientes en la estructura sociodemográfica de la ciudad de Valencia derivados de las transformaciones económicas experimentadas por la ciudad en el periodo posterior a la crisis, $y$, en particular, del proceso de turistificación que han vivido determinadas áreas urbanas. Para ello, se analiza el patrón territorial de los cambios residenciales en el interior de la ciudad central durante el periodo 2014-2017 y se pone en relación con la distribución espacial de la actividad turística y la localización de los proyectos urbanísticos recientes como forma de aproximación a este fenómeno en el conjunto de la ciudad. Se propone una metodología novedosa para el tratamiento de los microdatos demográficos de movilidad residencial y se concluye con una tipología de áreas dentro de la ciudad que ayuda a comprender las distintas dinámicas territoriales que han dado lugar a procesos de gentrificación de diferente estructura e intensidad.

Palabras clave: gentrificación; cambio residencial; turismo; Valencia

* Este artículo se ha elaborado en el marco del proyecto «Sostenibilidad social, conectividad global y economía creativa como estrategias de desarrollo en el Área Metropolitana de Valencia» (CSO2016-74888-C4-1R), financiado por la Agencia Estatal de Investigación (AEI) y el Fondo Europeo de Desarrollo Regional (FEDER) dentro del Programa Estatal de Investigación, Desarrollo e Innovación Orientada a los Retos de la Sociedad, en el marco del Plan Estatal de Investigación Científica y Técnica y de Innovación 2013-2016, convocatoria de 2016. 
Resum. Canvis econòmics, mobilitat residencial i gentrificació a la ciutat de València (20142017)

L'objectiu d'aquest article és identificar els canvis recents en l'estructura sociodemogràfica de la ciutat de València derivats de les transformacions econòmiques experimentades per la ciutat en el període posterior a la crisi, i en particular del procés de turistificació que han viscut determinades àrees urbanes. Per fer-ho, s'analitza el patró territorial dels canvis residencials a l'interior de la ciutat central durant el període 2014-2017 y es posa en relació amb la distribució espacial de l'activitat turística i la localització dels projectes urbanístics recents com a forma d'aproximació a aquest fenomen en el conjunt de la ciutat. Es proposa una metodologia nova per al tractament de les microdades demogràfiques de mobilitat residencial i es conclou amb una tipologia d'àrees dins de la ciutat que ajuda a comprendre les diferents dinàmiques territorials que han donat lloc a processos de gentrificació de diversa estructura i intensitat.

Paraules clau: gentrificació; canvis residencials; turisme; València

Résumé. Changements économiques, mobilité résidentielle et gentrification dans la ville de Valencia (2014-2017)

L'objectif de cet article est d'identifier les changements récents dans la structure socio-démographique de la ville de Valence résultant des transformations économiques que la ville a connues dans la période d'après-crise, et en particulier, du processus de touristification que certaines zones urbaines ont connu. À cette fin, le schéma territorial des changements résidentiels à l'intérieur de la ville centrale au cours de la période 2014-2017 est analysé, en le mettant en relation avec la répartition spatiale de l'activité touristique et la localisation des récents projets de développement urbain, afin d'aborder ce phénomène dans la ville dans son ensemble. Une nouvelle méthodologie est proposée pour le traitement des microdonnées démographiques de la mobilité résidentielle et elle se conclut par une typologie des zones de la ville qui aide à comprendre les différentes dynamiques territoriales qui ont donné lieu à des processus de gentrification de structure et d'intensité différentes.

Mots-clés : mouvements résidentiels ; gentrification ; tourisme ; Valencia

Abstract. Economic changes, residential mobility, and gentrification in the city of Valencia (2014-2017)

The aim of this article is to identify recent changes in the socio-demographic structure of the city of Valencia, Spain, resulting from the economic transformations the city experienced in the post-crisis period and, in particular, due to the touristification process that certain urban areas have undergone. To this end, the territorial pattern of residential changes in the interior of the central city during the period 2014-2017 is analyzed and related to the spatial distribution of tourist activity and the location of recent urban development projects as a way of approaching this phenomenon in the city as a whole. A novel methodology is proposed for the treatment of demographic microdata on residential mobility. The article concludes with a typology of areas within the city that helps to understand the different territorial dynamics that have given rise to gentrification processes of different structure and intensity.

Keywords: gentrification; residential change; tourism; Valencia 


\section{Sumario}

$\begin{aligned} \text { 1. Introducción } & \text { 4. La ciudad de Valencia: estructura } \\ \text { 2. Marco teórico: cambio residencial, } & \text { urbana y cambios económicos recientes } \\ \text { segregación y gentrificación urbana } & \text { 5. La movilidad residencial reciente } \\ \text { 3. Fuentes y metodología } & \text { en la ciudad de Valencia } \\ & \text { 6. Discusión y conclusiones } \\ & \text { Referencias bibliográficas }\end{aligned}$

\section{Introducción}

En los últimos años, las áreas metropolitanas han experimentado las consecuencias de lo que se ha denominado un nuevo ciclo económico, iniciado en 2013, marcado por la recuperación de la inversión inmobiliaria y la presencia de nuevos operadores que compiten con los tradicionales por repartirse el negocio urbano (Méndez, 2019: 14). Este nuevo contexto ha incidido en la estructura y la morfología metropolitanas y ha provocado nuevos y agravados problemas sociales. Una de las consecuencias espaciales más importantes es la revalorización de las áreas centrales, convertidas en nuevos espacios de oportunidad para los inversores financieros, lo que conlleva en ocasiones la expulsión de los anteriores residentes y su sustitución por otros segmentos sociales más acomodados, en un proceso conocido como gentrificación. En este proceso intervienen, además de factores culturales y sociales, nuevos actores financieros, como los fondos de inversión y la creciente presencia de compradores extranjeros, atraídos por la oportunidad de negocio que proporciona el aumento de la demanda en el mercado del alquiler, acentuada por la expansión del turismo urbano y la proliferación de alojamientos de uso turístico (Méndez, 2019: 234).

La irrupción de la pandemia COVID-19 ha cortado en seco esta tendencia, con la restricción de la movilidad y, por tanto, del turismo, y ha generado incertidumbre sobre el futuro de las áreas centrales de las metrópolis, que pueden verse afectadas por aceleradas dinámicas descentralizadoras debido al miedo al contagio y al declive del comercio y las actividades de ocio de los espacios urbanos centrales. Estas dinámicas pueden ser especialmente importantes en el caso de las clases educadas y adineradas, que constituyen la fuerza motriz de los procesos de reactivación y gentrificación de los centros urbanos (Florida et al., 2020). El aumento del teletrabajo y la crisis de las actividades comerciales y de ocio de los centros urbanos pueden provocar un descenso de la demanda, y, por tanto, de los precios, que haga menos atractivos estos espacios centrales para el capital financiero (Reuschke y Felstead, 2020). Sin embargo, todavía es pronto para evaluar, o incluso predecir, el impacto de estos procesos sobre la estructura urbana, ya que este está condicionado por la duración y letalidad de la pandemia, así como por los efectos de fuerzas contradictorias como el refuerzo de las dinámicas de proximidad debido a las reticencias al uso del transporte público (Florida et al., 2020). 
En cualquier caso, las consecuencias de la dinámica previa a la pandemia ya se han hecho visibles en la estructura social de las ciudades (Musterd et al., 2015; Recaño Valverde y Bayona-i-Carrasco, 2016; Tammaru et al., 2016; López-Gay, 2018; Sorando y Leal, 2019), de forma que procesos derivados, como los de segregación residencial, desigualdad y gentrificación, han pasado a la primera línea del interés de los científicos sociales y de los políticos (Sorando y Leal, 2019; Lopez-Gay et al., 2020). A lo largo del siglo xx se consolidó un modelo urbano en las ciudades del sur de Europa en el que el incremento de la desigualdad socioeconómica no suponía una segregación residencial (Leal y Sorando, 2016). Sin embargo, esta situación parece estar cambiando en las primeras décadas del siglo actual, en el que se detecta que un aumento de la desigualdad socioeconómica se traduce también en una separación espacial (Domínguez et al., 2012). Ello es debido a una serie de circunstancias interrelacionadas, entre las que destacan la expansión inmobiliaria y la crisis económica, así como el posicionamiento de la ciudad en los flujos globales y, como una de sus consecuencias, no la única, el aumento de la demanda turística.

La ciudad de Valencia, como otras áreas metropolitanas europeas y españolas, ha experimentado en los últimos años un cambio significativo en su perfil económico, en línea con lo anteriormente señalado. Por un lado, se ha producido un importante aumento de la actividad turística que, junto con los efectos de la crisis económica sobre el sector industrial, ha intensificado la especialización terciaria del conjunto urbano, y ha dado lugar a la creación de espacios urbanos transformados morfológica y socialmente. En algunos de ellos se ha originado un intenso cambio sociodemográfico, con salida de la población residente y entrada de nuevos vecinos, que, en algunos casos, ha llevado a un cierto vaciamiento residencial. Estos nuevos espacios segregados se unen a los resultantes de la política neoliberal de grandes proyectos implementada desde los años 1990 (Salom y Pitarch, 2017), que generó espacios diferenciados socialmente, como los nuevos barrios creados en el entorno de la Ciutat de les Arts i les Ciències (Santamarina y Moncusí, 2013; Santamarina, 2014). Por otra parte, en los últimos años, se han puesto en marcha algunos nuevos proyectos de regeneración urbana que han creado expectativas inmobiliarias cuyos efectos socioterritoriales todavía están por evaluar (Ilisei y Salom, 2018).

El objetivo de este artículo es conocer y analizar la segregación espacial en la ciudad de Valencia a partir de procesos de cambio demográfico durante el periodo 2014-2017 con el fin de aproximarnos a una identificación de los procesos de gentrificación. Para ello se analiza el patrón espacial de los cambios residenciales en el interior de la ciudad, y se identifican aquellos espacios en donde se ha producido un cambio sociodemográfico importante, con el fin de relacionarlo con los cambios territoriales producto de la actividad económica urbana, en particular del crecimiento de la actividad turística.

El artículo se estructura de la siguiente forma: en el apartado siguiente (punto 2) se presenta el marco teórico que sustenta la relación entre turismo, gentrificación, y cambios residenciales. En el apartado 3 presentamos las fuentes, metodología y técnicas de análisis. En el punto 4 analizamos los 
principales procesos de cambio económico experimentados por la ciudad de Valencia, y en el apartado 5 realizamos el análisis de los cambios residenciales, para concluir con un punto final de discusión y conclusiones.

\section{Marco teórico: cambio residencial, segregación y gentrificación urbana}

La configuración socioespacial de las ciudades está experimentando transformaciones constantemente, pero en particular desde comienzos del presente siglo. Las dos primeras décadas del siglo XXI han visto la rápida expansión de un proceso de elitización en determinadas zonas dentro de las ciudades a partir de la localización de nuevas actividades económicas y culturales que generan el desplazamiento de la población con menos recursos hacia espacios con peor acceso a los servicios, lo que agudiza problemas vinculados a la segregación espacial. Como señalan Sorando y Leal (2019), la segregación urbana que supone la agrupación de individuos de renta baja, en riesgo de exclusión o en situación de pobreza, puede suponer que el apoyo mutuo propio de la solidaridad entre iguales se vea muy limitado. Ello repercute negativamente no solo en la población más desfavorecida, sino en el conjunto de la ciudad, en su capacidad de resiliencia frente a crisis de todo tipo y en su competitividad exterior.

Han sido muchos los estudios realizados desde las ciencias sociales, en particular la sociología y la geografía, sobre desigualdad y exclusión en espacios urbanos (Gale, 1985; Sassen, 1991; Musterd, 2006; Donat, 2018), en especial sobre la relación entre el incremento de la desigualdad socioeconómica y el aumento de la segregación residencial, así como sobre la mezcla social (propia de la evolución de las ciudades europeas), aspectos clave en las aportaciones teóricas y prácticas sobre la llamada nueva cuestión urbana (Merrifield, 2013; Lees et al., 2016; Méndez, 2019).

El primero de los fenómenos señalados — la transformación social de determinados espacios dentro de la ciudad que se convierten en exclusivos ( $\mathrm{y}$ excluyentes)—, está claramente vinculado al concepto de gentrificación. Este término nació a mediados de los años sesenta del siglo pasado a partir de los estudios de la socióloga Ruth Glass (1964) para definir las consecuencias del cambio residencial de la población londinense de clase media a los barrios en los que anteriormente residía la clase baja, que se ve obligada a trasladar su residencia ante la imposibilidad de afrontar los procesos de rehabilitación y revalorización del suelo. En la actualidad, ha adquirido un significado más profundo y, sobre todo, más complejo. Gentrificación supone transformación sociodemográfica de determinadas áreas, fundamentalmente urbanas (hoy se analiza también la gentrificación rural), provocada por la llegada de personas de renta media-alta que desplazan a las personas con menos recursos -en principio, un desplazamiento no deseado- , con causas diversas: resultado de políticas públicas, de estrategias de actores privados en el mercado inmobiliario o de aspiraciones residenciales de personas particulares que se sienten atraídas hacia determinados barrios renovados (Solana et al., 2016; Donat, 2018; Gomà, 2018). Es una línea fina la que separa la mejora de la calidad de vida de 
un barrio del reemplazo — no deseado- de su población por otra de mayor nivel económico. Como señala Gomà (2018), este proceso de expulsión tiene una dimensión urbanística, ya que se evidencian y agudizan la desinversión y degradación física, seguidas de reinversión en capital fijo, que incrementan el precio de la vivienda tanto de compra como de alquiler, lo que genera la llamada brecha de renta y comporta, a su vez, una sustitución de clase, unas nuevas pautas de uso del espacio, un nuevo entramado de relaciones sociales, etcétera.

Al mismo tiempo, con las consideraciones oportunas, algunos autores abogan por un proceso de cierta gentrificación, o de gentrificación socialmente aceptable, que genera revitalización y revalorización de determinados barrios (Nel.lo, 2001; Sabatini et al., 2010; Ghaffari et al., 2017), estimulados por la atracción de población nueva y variada, con una renta elevada, pero evitando la segregación de los más pobres. Todo ello es de suma importancia desde el punto de vista político, pues las decisiones sobre determinados aspectos de la ciudad, tanto urbanísticos como sociales, inciden claramente en la agudización del proceso en un sentido $\mathrm{u}$ otro.

Por tanto, como indica Checa-Artasu (2011), la gentrificación es un concepto ambivalente, que supone éxito para algunos y efectos no deseados y perniciosos para otros, como respuesta a la inserción del capitalismo en lo urbano a través de la transformación de los espacios en busca de rendimiento a corto plazo, a lo que se añade que es percibido como un fenómeno inevitable en las áreas urbanas globales. En definitiva, aunque el proceso de gentrificación se detecta a nivel local o de barrio, en realidad se enmarca en el contexto de la globalización (Sassen, 1991; Smith, 2002; Benach y Albert, 2018; Mitchell, 2018), ya que no es sino la expresión real, personal incluso, de los movimientos de capital. Para algunos autores, la gentrificación, fenómeno generalizado en las grandes ciudades del mundo, se entiende como una estrategia urbana global, que es parte del urbanismo neoliberal (Smith, 2002; Lees et al., 2016).

A pesar de las distintas posiciones sobre el fenómeno de la gentrificación, lo que es indiscutible es que se trata de un concepto de difícil medición por distintas razones, como la dificultad para obtener datos sobre las inversiones inmobiliarias a microescala o el hecho de que solo se realicen estudios de espacios que son percibidos previamente como gentrificados (López-Morales, 2013; Rubiales et al., 2012). A ello hay que añadir la falta de evidencia empírica sobre la magnitud de los desplazamientos y sus motivaciones (Easton et al., 2020). Por otra parte, muchos estudios no reconocen la alta incidencia que tiene el Estado (la administración local particularmente), a través de sus instrumentos de regulación de la construcción inmobiliaria y de usos del suelo que, a medio y largo plazo, van reconfigurando física y socialmente la ciudad y, por tanto, generando procesos de gentrificación en determinados espacios (López-Morales, 2013; Rubiales et al., 2013). Algunas de las metodologías para acercarse a este fenómeno de manera cuantitativa incluyen el análisis de los datos censales y padronales, fundamentalmente el análisis de los cambios residenciales (Bayona-i-Carrasco et al., 2018; Sorando y Leal, 2019), incluso formando parte de índices e indicadores para detectar la aparición de gentrificación y su magnitud, que incluyen, además, 
aspectos como los niveles de cualificación, el precio de las viviendas y la estructura de los hogares, entre otros (López-Gay et al., 2019). En definitiva, las pautas y los procesos que suponen desplazamiento de la población residente pueden inferirse a través de las fuentes de datos existentes, que ayudan a dar una primera imagen sobre este fenómeno, siempre teniendo en mente la necesidad de considerar las características del contexto urbano y la disponibilidad de información sociodemográfica existente (López-Gay et al., 2019), así como complementar los resultados con información cualitativa que puede aportar explicaciones a los fenómenos que los datos cuantitativos no revelan.

A las causas señaladas en los párrafos anteriores hay que añadir otras cuestiones, entre las que destaca el desarrollo del turismo. Este fenómeno se encuentra en la raíz de lo que a veces se denomina elitización (Lees et al., 2016; Rubiales et al., 2012), aunque es una nueva forma, propia de nuestra época, de gentrificación (Gotham, 2005; Füller y Michael, 2014; Cocola-Gant, 2018; Arias Sans, 2018). Cuando se produce un fenómeno de turistificación en la ciudad, la afluencia de turistas suele venir acompañada de la proliferación de pisos en alquiler vacacional y la aparición de establecimientos comerciales que cubren las demandas de los visitantes, y que ocuparán el lugar de los comercios tradicionales. El turismo, como fenómeno global, al igual que la gentrificación, tiene una gran capacidad transformadora, que no responde únicamente al aumento de visitantes, sino a una construcción material y simbólica de la ciudad que se imbrica en otros aspectos que también contribuyen a definir la nueva realidad urbana (Arias Sans, 2018). Estos procesos han generado críticas contundentes por parte de la sociedad (movimientos vecinales en contra de la turistificación) y de la academia (Smith, 2002; Cameron, 2003; Hiernaux, y González, 2014; Janoschka, 2016), y también políticas locales de control del fenómeno, aunque con diverso grado de éxito. En la actualidad, lo que es indiscutible es que el fenómeno turístico contribuye a la gentrificación, o muy probablemente ambos procesos se refuerzan mutuamente, por lo que es necesario considerarlo en el análisis y cuantificarlo. Un gran número de estudios han considerado el fenómeno del alquiler vacacional como una de las formas de acercarse al proceso de gentrificación en grandes ciudades, lo que ha evidenciado la interdependencia entre turismo y exclusión (expulsión) o turismo y gentrificación (Arias-Sans i Quaglieri, 2016; Duatis et al., 2016; Horn y Merante, 2017; Amore et al., 2020).

En el momento actual, en plena crisis pandémica por el COVID-19, hay autores que ya preconizan un desigual impacto sobre los espacios anteriormente gentrificados, al suponer que, cuando se retome el tránsito turístico normal, surgirán nuevas prácticas y nuevos motivos para continuar nuevos procesos de gentrificación (Alexandri y Janoschka, 2020).

La ciudad de Valencia, como otras ciudades europeas, también ha experimentado procesos de gentrificación, tanto a consecuencia del desarrollo de dinámicas urbanas neoliberales desde los años ochenta del siglo pasado como a consecuencia del extraordinario aumento del número de visitantes desde entonces. Los poderes públicos locales han promovido estos procesos hasta 
una época reciente, mediante un urbanismo de grandes proyectos urbanos y de acogida de eventos de carácter internacional, con la colaboración de la iniciativa privada. La ciudad de Valencia, al contrario que otras urbes españolas, se ha caracterizado por la mayor dureza de la política neoliberal, que no fue acompañada de otras políticas de carácter social (Cucó, 2013). Sin embargo, nunca se ha analizado este fenómeno para el conjunto de la ciudad, y con datos procedentes de fuentes como son la estadística de altas y bajas al padrón o la oferta de apartamentos turísticos en las llamadas plataformas colaborativas (Airbnb).

\section{Fuentes y metodología}

\subsection{Fuentes estadisticas e indicadores}

La principal fuente estadística utilizada en este artículo para analizar el patrón espacial de los cambios residenciales a escala detallada es la información de microdatos de variaciones residenciales durante el periodo 2014-2017, proporcionada por la Oficina de Estadística del Ayuntamiento de Valencia. Estos microdatos contienen, entre otros aspectos, información sobre nivel educativo de la persona que cambia de residencia, que ocasiona alta o baja en una sección censal concreta, así como del lugar de origen o destino de cada desplazamiento. Los datos incluyen las altas por otros motivos (en las que se desconoce el origen) y las bajas de las que no se conoce el destino o por omisión (emigraciones sin declarar, inscripciones que no han sido renovadas o dadas de baja), lo que nos permite incluir la entrada/salida de población desde y hacia el extranjero en el saldo de los movimientos residenciales ${ }^{1}$.

Esta fuente de información nos facilita descender al detalle de la dinámica espacial de la movilidad residencial a escala de sección censal ${ }^{2}$, con una aproximación a las dinámicas sociales asociadas a través de la variable nivel educativo, que a efectos del presente análisis hemos agrupado en dos categorías: inferior, o igual o superior a bachiller, FP segundo grado y equivalentes ${ }^{3}$. Debido a que

1. La comparación realizada con los datos proporcionados por el INE nos confirma la necesidad de incluir en el cálculo las altas y sobre todo las bajas por otros motivos, ya que muchas de ellas son emigraciones definitivas que no se comunican. La incorporación de estos datos puede sobredimensionar ligeramente los movimientos de la población española, pero resulta imprescindible a la hora de evaluar los cambios experimentados por la población extranjera, sobre todo la nacional de países de fuera de la UE, que constituyen una parte muy importante del total.

2. Debido a los cambios experimentados a lo largo de los años analizados y la necesidad de utilizar una división censal homogénea para el conjunto del periodo, se ha utilizado como base territorial la división censal de 2016 con la agregación de dos secciones censales, tomando como referencia la información proporcionada por el Ayuntamiento de Valencia.

3. La información proporcionada, con el fin de respetar el secreto estadístico, agrupa los niveles educativos en las siguientes categorías: Menor de 18 años, No sabe leer y escribir, Titulación inferior a graduado escolar, Graduado escolar y equivalente; y Bachiller, FP segundo grado y equivalentes, o superior. Es por esto que en el presente análisis se utiliza este último grupo como indicador de los procesos de elitización, en vez de la población con estudios superiores o de tercer grado, como se hace en otros estudios similares. 
los patrones de movilidad son muy diferentes, en el análisis hemos diferenciado también entre el saldo y tasa derivada de cambios residenciales internos al municipio (cambios entre secciones censales), y el saldo y tasa derivados de las altas y bajas cuya procedencia o destino estén situados fuera del municipio, sea este un municipio de la corona metropolitana, uno del resto de España o uno de otro país. En el presente artículo denominamos al primero saldo o tasa de cambio residencial, y al segundo saldo o tasa de migración externa, y reservamos el término saldo o tasa migratoria total para la suma de ambos tipos de movimientos.

El análisis se ha realizado para el periodo comprendido entre el 1 de enero de 2014 y el 1 de enero de 2018, una etapa caracterizada por la reactivación de la actividad económica y de los mercados inmobiliarios que se ha visto incentivada por un notable incremento en los precios de la vivienda ${ }^{4} \mathrm{y}$ por la intensificación del desarrollo turístico de la ciudad. Además, el inicio del periodo coincide con el año a partir del cual la información de niveles educativos recogida en el padrón de habitantes tiene, según información proporcionada por el ayuntamiento, suficiente fiabilidad como para ser objeto de análisis 5 . Una exploración previa de los datos ha permitido constatar que, pese a la tendencia a la intensificación de la movilidad, los patrones espaciales de los cuatro años analizados son similares, por lo que el periodo estudiado tiene la suficiente coherencia interna como para ser tratado de forma conjunta. La localización geográfica de los saldos de movilidad residencial nos permite elaborar un mapa de la tendencia a la especialización de cada una de las secciones censales en un subgrupo sociodemográfico determinado, lo que nos indica la posible existencia de dinámicas de segregación de clases altas o bajas, gentrificación o procesos similares.

Por otra parte, para el análisis de la actividad turística se han utilizado los datos de apartamentos turísticos anunciados en la plataforma Airbnb a partir de la página del proyecto colaborativo Hippo, que proporciona información procedente de varias plataformas de alquileres turísticos para el periodo 20172018 (<https://datahippo.org/es/>). La información recogida se refiere a los anuncios activos en la plataforma durante el periodo mediante un proceso de scraping que se realiza periódicamente, desde agosto de 2017 a septiembre de 2018.

4. Un incremento del $31 \%$ entre 2013 y 2018, próximo al experimentado por Madrid $(+36,1 \%)$ y muy por delante de los de otras ciudades como Sevilla $(+6,4 \%)$ y Bilbao (-0,9\%), según Méndez (2019: 202).

5. El certificado o título académico que se posee es un dato de inscripción obligatorio para el empadronamiento y debe recogerse adecuadamente, ya que, al margen del interés estadístico que pueda suponer, tiene una clara finalidad en los procesos electorales (artículo $26.2 \mathrm{de}$ la LOREG), por lo que es objeto de distintos procesos de verificación por el INE (<http:// blogpadron.absis.es/nivel-de-estudios-parte-i/>). La calidad de la información sobre el nivel educativo incluida en el padrón de habitantes, que anteriormente no era muy buena, ha mejorado notablemente en los últimos años, debido a la actualización automática que se realiza a partir del registro de títulos del Ministerio de Educación, lo que permite un análisis pormenorizado de esta variable. 


\subsection{Metodología y técnicas}

Tal y como se ha referido anteriormente, el objetivo de este artículo es analizar el impacto producido por los cambios económicos experimentados por la ciudad de Valencia en el periodo 2014-2017 sobre el modelo territorial desde el punto de vista de la estructura sociodemográfica urbana y, en particular, aproximarnos a la identificación de los procesos de cambio demográfico que puedan estar relacionados con procesos de gentrificación. Es evidente que un proceso multidimensional como la gentrificación requiere una combinación de aproximaciones cualitativas y cuantitativas para ser captado en toda su complejidad, sin embargo, nuestro objetivo aquí es identificar, mediante una aproximación principalmente cuantitativa, los espacios urbanos en que se están produciendo procesos de sustitución demográfica que puedan ser interpretados como procesos de gentrificación más o menos avanzados. De forma más específica, pretendemos dar respuesta a las siguientes cuestiones: 1) ¿cuál es el patrón espacial de los cambios residenciales de la población educada en la ciudad durante el periodo reciente?, 2) ¡es posible identificar espacios con tendencia a la segregación sociorresidencial, sea de clases altas, sea de clases bajas, así como espacios en donde se está produciendo un proceso de sustitución entre estos dos grupos?, y 3) ¿qué relación guardan estos espacios con las transformaciones recientes de la actividad económica en la ciudad $y$, en particular, con el incremento de la actividad turística y el desarrollo de proyectos urbanos?

La identificación de patrones espaciales y la detección de las áreas con cambio sociodemográfico significativo se han basado en la aplicación de distintas técnicas fundamentadas en la autocorrelación espacial: interpolación kriging ${ }^{6}$, cálculo del índice I de Moran Global y detección de clústeres espaciales mediante Getis-Ord Hot Spot Analysis. La autocorrelación espacial permite medir la significación de la asociación entre valores próximos, sea a escala del conjunto del área de estudio, sea en función de la distancia que separa las observaciones, lo que permite detectar clústeres locales de valores similares en magnitud.

El cálculo del índice global de autocorrelación espacial, o I Global de Moran, se ha aplicado a las tasas migratorias en cada una de las categorías sociodemográficas estudiadas a distintas distancias, lo que ha permitido detectar simultáneamente si existe algún proceso de autocorrelación espacial en la distribución de los valores o si esta es aleatoria, y, en el primer caso, a qué distancia este fenómeno actúa con un mayor nivel de significación 7 . Por su

6. Esta técnica de interpolación espacial se basa en una estimación de la autocorrelación espacial en función de la distancia y la orientación a partir de un punto dado, lo que permite una predicción de la variación de los valores y la detección de tendencias de variación locales (Lloyd, 2010). En nuestro caso, se ha aplicado kriging ordinario, con un modelo de semivariograma esférico, con la aplicación de un tamaño de celda de $50 \mathrm{~m}$ de resolución y un radio de búsqueda variable de 12 puntos.

7. El cálculo se ha realizado mediante la herramienta Incremental Spatial Autocorrelation de ArcGis, que mide la intensidad del agrupamiento espacial a una serie de distancias crecientes a partir del cálculo de la puntuación estimada del índice de Autocorrelación I de Moran. 
parte, la aplicación del índice Getis-Ord Hot Spot Analysis o GI* ha permitido localizar el agrupamiento de valores altos y bajos, e identificar así la localización de espacios concretos dentro de la ciudad que muestran un comportamiento específico en relación con los cambios residenciales. El valor del índice indica la existencia de un agrupamiento de valores altos (hot spots, valores positivos) o bajos (cold spots, valores negativos), con la medición además del nivel de significación de dichos valores. La herramienta utilizada es el Optimized Hot Spot Analysis de ArcGis ${ }^{8}$.

Los análisis anteriores han permitido identificar la existencia de un patrón espacial para las dinámicas de cambio sociodemográfico en la ciudad de Valencia diferenciando en función del tipo de movimiento y subgrupo de población, así como detectar las localizaciones en que estas dinámicas alcanzan un valor significativo, lo que apunta a un proceso implícito de segregación.

Como último paso, se ha aplicado un análisis de agrupamiento espacial (grouping) a las secciones censales para establecer una tipología de comportamiento que pueda apuntar a procesos sociales, económicos y residenciales diferenciados. Este análisis de agrupamiento considera, de forma parecida a otros análisis de este tipo, la similitud de los casos a partir de un conjunto de variables, y los clasifica mediante un proceso de división iterativa, pero introduce una restricción espacial en la formación de los grupos, de modo que garantiza grupos compactos, formados por elementos contiguos o próximos ${ }^{9}$.

Los espacios así identificados se han contrastado con las áreas en donde los procesos de turistificación han sido más intensos, con el fin de evaluar si existe relación entre ambos procesos y en qué casos es posible identificar esta relación o la existencia de otro tipo de procesos urbanos.

\section{La ciudad de Valencia: estructura urbana y cambios económicos recientes}

\subsection{Segregación y diferenciación social interna}

La identificación de los efectos territoriales de los procesos recientes debe apoyarse en el conocimiento de la estructura socioeconómica espacial previa sobre la que estos actúan. La ciudad de Valencia ha experimentado cambios en los últimos treinta años producto de diferentes procesos de orden local y global.

8. Esta herramienta introduce una serie de pasos previos al cálculo del índice que permite mejorar y asegurar la significación de los resultados: $a$ ) verifica que el número de casos sea suficiente para el análisis, $b$ ) busca outliers locacionales y los elimina del cálculo de banda de distancia óptima; $c$ ) averigua la banda de distancia óptima calculando la intensidad de agrupamiento a diferentes distancias; $d$ ) encuentra los valores agrupados significativamente, e) determina el porcentaje de los valores con escasos vecinos, y $f$ ) cartografía los resultados (Esri, 2020).

9. La restricción espacial que hemos introducido es la de K-Nearest Neighbors, en que k=8. Esta opción supone que una entidad solo será incluida en un grupo si al menos otra entidad de este grupo es un vecino más próximo, siendo en este caso considerados los ocho vecinos más próximos. 
Siguiendo a Salom y Fajardo (2017), en la primera década del siglo xxI, la ciudad y su área metropolitana se caracterizan por un aumento de la polarización geográfica y de los contrastes sociodemográficos internos. Los factores que contribuyen a esta polarización son la llegada de inmigración, el aumento de la segregación socioeconómica, tanto de rentas altas como bajas, y el elevado nivel de desarrollo inmobiliario vinculado a proyectos urbanísticos ligados a factores ajenos al crecimiento demográfico del municipio.

Tras la crisis económica de 2008, y fundamentalmente durante la segunda década del actual siglo, la ciudad sufre las consecuencias de la recesión de forma más intensa que otras ciudades españolas, lo que lleva a algunos a abandonarla por motivos económicos: muchos inmigrantes regresan a sus países de origen y un número importante de jóvenes emigran a otras regiones o países en busca de trabajo. Durante la segunda mitad de la última década, se consolidan procesos de reorganización interna que ya existían anteriormente, que evidencian una concentración de grupos sociales similares, lo que supone un cierto grado de segregación, como es el caso de los extranjeros procedentes de la UE con elevada cualificación, que se ubican preferentemente en determinados barrios o áreas como son el casco histórico, el primer ensanche, la zona cercana a la playa y el nuevo barrio creado en torno a la Ciutat de les Arts i les Ciències (figura 1).

Las figuras 2 y 3 muestran una aproximación a la estructura territorial socioeconómica de la ciudad a través de la distribución espacial de la población con mayor nivel de estudios, por un lado, y del indicador de renta media elaborado por el INE (INE, 2019), por otro. En ellas puede observarse la existencia de varias zonas diferenciadas. Por un lado, un área que se corresponde mayoritariamente con los espacios del centro de la ciudad, donde la población con mayor nivel educativo supera el $70 \%$ del total, y la renta media pasa de los 15.000 euros. Esta zona central contrasta con las áreas en donde predomina la población con bajos estudios, que en su mayoría presentan además altos porcentajes de población extranjera procedente de países de baja renta, ubicada mayoritariamente en la periferia de la ciudad.

Por tanto, podemos decir que, aunque los niveles de segregación urbana son bajos, sí se aprecia una cierta acumulación de grupos sociales similares en algunos barrios de la ciudad que, además, responden a una tradición histórica social y morfológica que explica dicha concentración. Sobre esta estructura territorial están actuando nuevos procesos que pueden dar lugar a significativos cambios territoriales, a los que hacemos referencia a continuación.

\subsection{La turistificación urbana}

La ciudad de Valencia ha experimentado desde principios de siglo un aumento espectacular en la llegada de visitantes, tanto turistas como excursionistas (Salom y Pitarch, 2017). A pesar del leve estancamiento durante la primera parte de los años de la crisis (de 2007 a 2012), la cifra de turistas que recibe la ciudad ronda los 1,8 millones anuales (el peor año fue 2010, con 1.500 .000 viajeros). El gasto total de los turistas en la ciudad es de unos 340 millones de 
Figura 1. Porcentaje de población mayor de 25 años que es nacional de la Unión Europea y tiene nivel educativo de bachiller o más, 2016

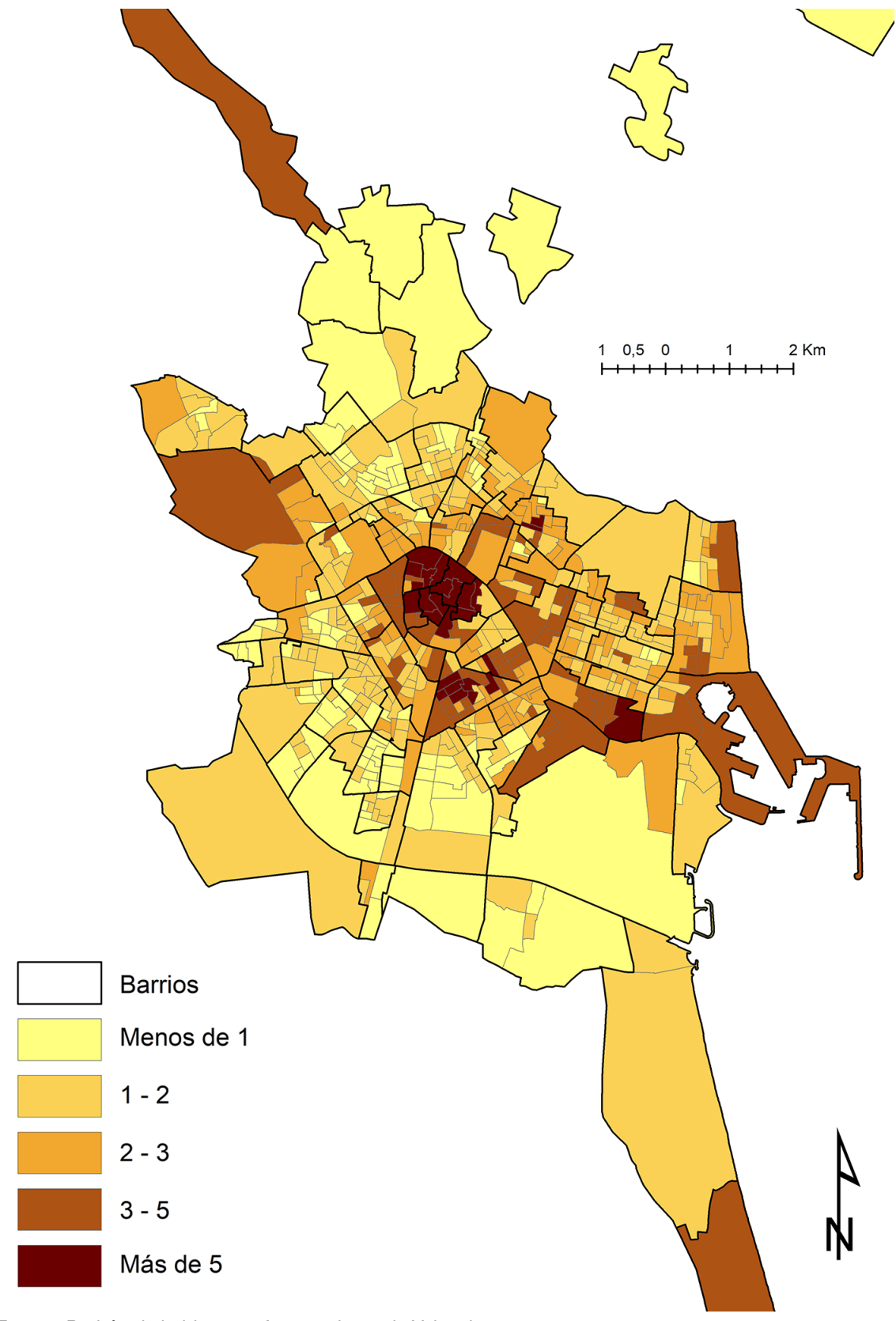

Fuente: Padrón de habitantes, Ayuntamiento de Valencia. 
Figura 2. Porcentaje de población mayor de 25 años con nivel educativo de bachiller o más, 2016

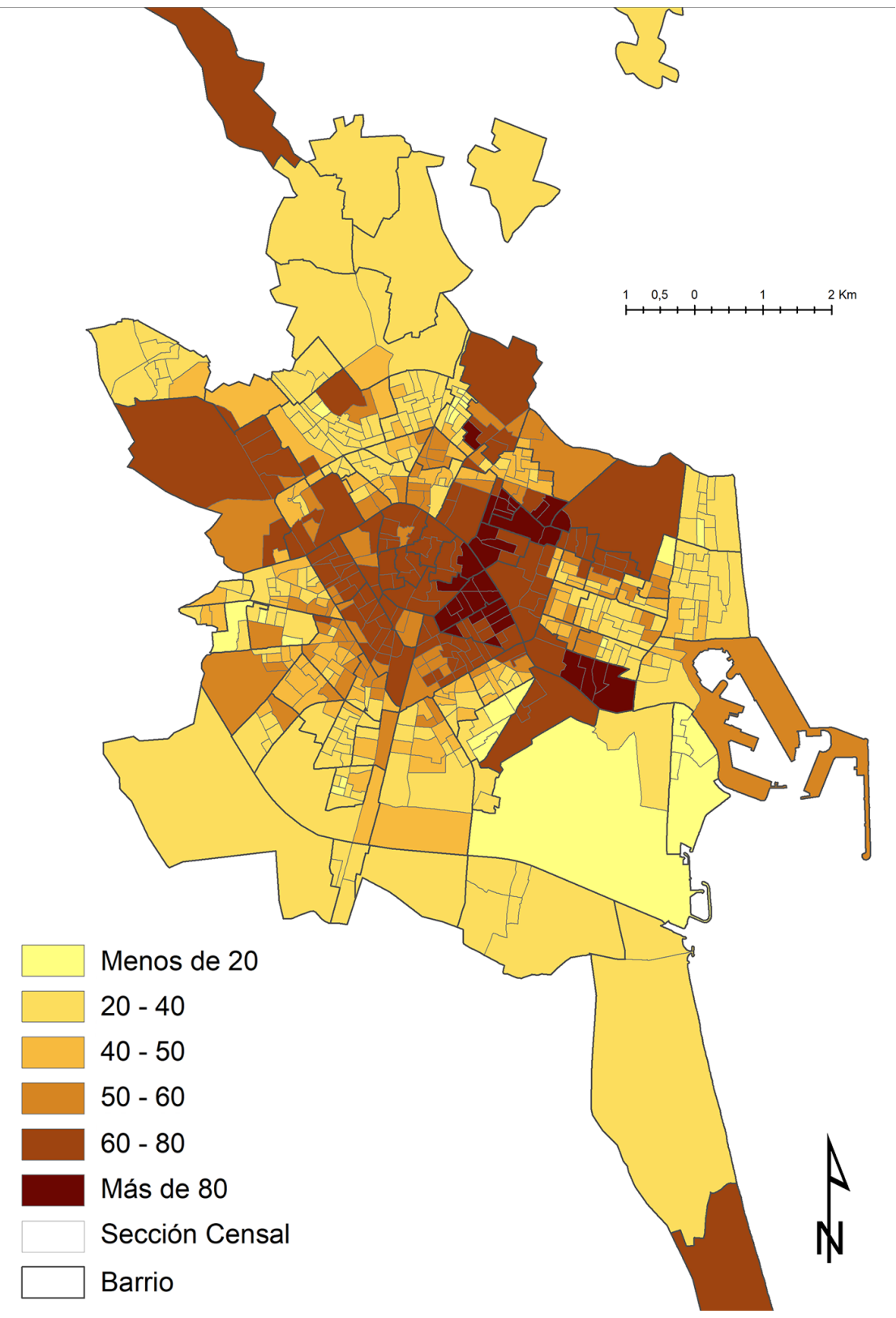

Fuente: Padrón de habitantes, Ayuntamiento de Valencia. 
Figura 3. Renta media (miles de euros) en 2015

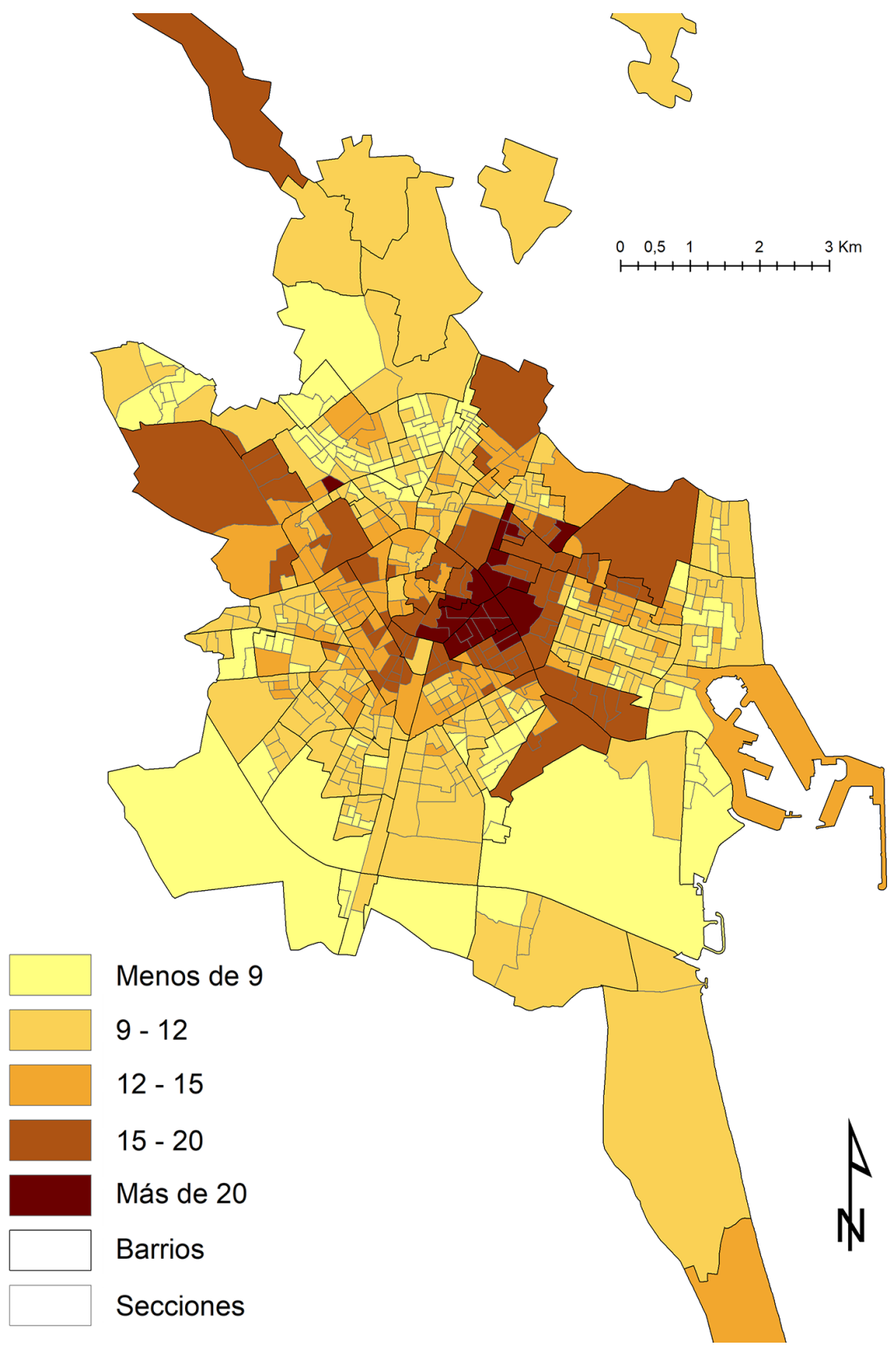

Fuente: INE, Atlas de distribución de renta de los hogares. 
Figura 4. Plazas de alojamiento turístico por distrito en Valencia, 2018

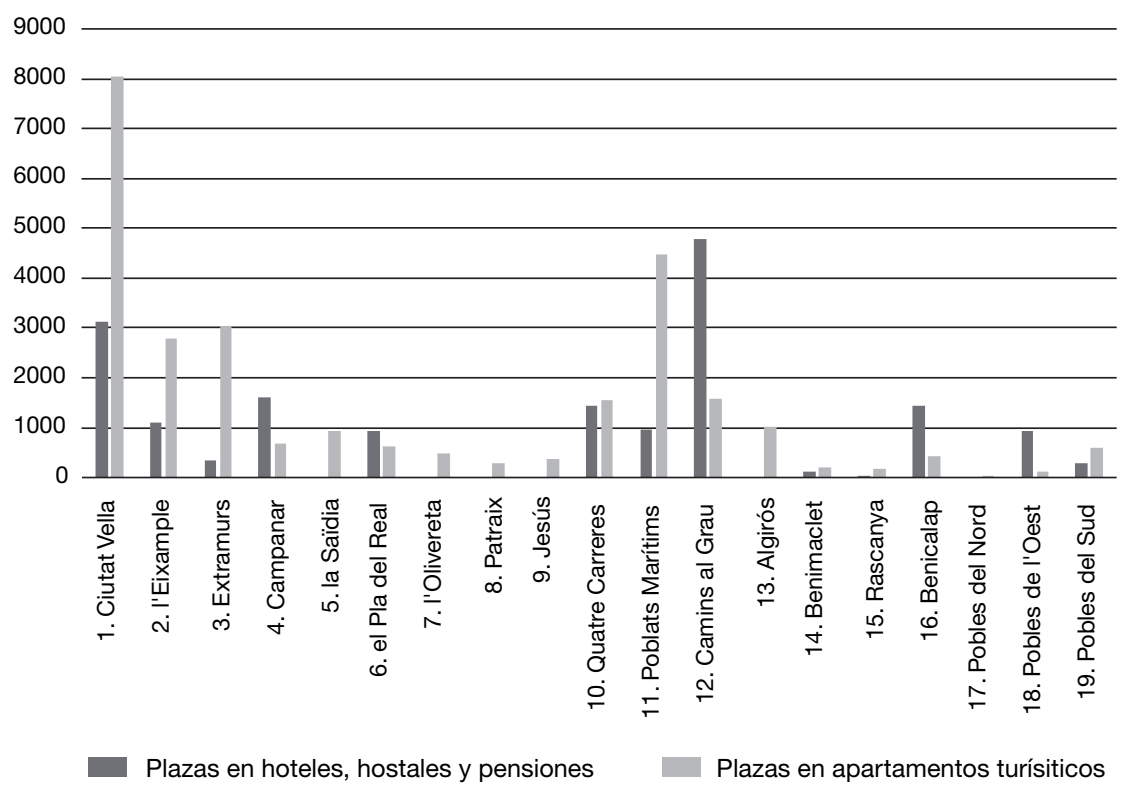

Fuente: Oficina de Estadística del Ayuntamiento de Valencia.

euros anuales, y el número de plazas de alojamiento se duplicó entre 2000 y 2007. En 2018, el número de plazas en hoteles, pensiones y hostales ascendía a más de 18.400 , y en apartamentos a más de 27.500 plazas, según datos del Ayuntamiento de Valencia. Sin embargo, según la misma fuente, las pernoctaciones en el primero de los tipos de alojamiento señalados superan los 4 millones, mientras que en los apartamentos rondan las 378.000.

Una forma de apreciar el crecimiento del turismo en esta ciudad es la evidencia del formidable aumento de la oferta de plazas turísticas en apartamentos, que en números globales supera ampliamente la oferta de alojamiento turístico más ortodoxa, especialmente en algunas zonas de la ciudad (figura 4). La proliferación de plataformas colaborativas para compartir vivienda (completa o por habitaciones) ha sido un impulso más para el turismo, especialmente en las ciudades, dado que, aunque no es esta la finalidad inicial declarada de estas plataformas, los turistas necesitan un alojamiento por un tiempo relativamente corto que el modelo de «compartir casa» facilita, ya que ofrece, además - tal como se declara en algunos de los anuncios-, la posibilidad de una experiencia más auténtica, al participar de la vida de la población autóctona. Esta nueva forma de entrar en el mercado, que algunos han llamado «capitalismo de plataforma» (Vallas y Kovalainen, 2019), está modificando la manera de entender el turismo, al democratizarlo aún más (debido a los precios más competitivos) y pasar de «compartir» a «alquilar», y por tanto compitiendo con 
los alojamientos turísticos tradicionales, pero con consecuencias sobre el territorio. Esto ocurre especialmente en las ciudades con un patrimonio cultural más atractivo o mejor mercantilizado, que se han visto obligadas a legislar para frenar el fenómeno de los apartamentos turísticos, en principio sin regulación. En particular, esto es debido al fuerte rechazo que existe por parte de la población residente a las prácticas asociadas al mismo, con consecuencias como la gentrificación de algunos barrios, que genera desplazamientos no deseados de la población y sustitución de la misma por otro tipo de residentes con mayor aceptación de los procesos de turistificación asociados (Cocola-Gant y LópezGay, 2020). Entre las empresas que facilitan el contacto entre oferta y demanda y que se autodenominan colaborativas o P2P (es decir, entre pares), destaca Airbnb.com. Fundada en 2008, Airbnb es la mayor empresa de este tipo del mundo, con más de 2 millones de viviendas para alquilar en más de 190 países (Horn y Merante, 2017).

En la ciudad de Valencia, como en todas las ciudades, los visitantes se concentran en espacios específicos, emblemáticos y visitables. La oferta de pisos turísticos también sigue el mismo patrón, que evidencia claramente su vinculación con este mercado (figuras 5 y 6 ). Tanto si consideramos el número de plazas por habitante o por hectárea, la concentración de la oferta se da en dos espacios concretos: el centro de la ciudad, coincidiendo con el casco histórico y con el barrio de Russafa, muy vinculado a la historia de la ciudad y con personalidad propia (Romero y Lara, 2015), y los barrios cercanos a la playa, tanto al norte como al sur del puerto, es decir Cabanyal-Canyamelar y El Saler.

El análisis de la localización de la oferta de Airbnb nos permite identificar los espacios más afectados por el fenómeno turístico. Con el estudio sociodemográfico de la ciudad que realizamos más adelante, podremos identificar si este fenómeno ha generado, como dicen algunos autores, procesos de desplazamiento de la población local que puedan estar relacionados con la gentrificación. Sin embargo, esta puede estar provocada no solo por la actividad turística, sino también por la acción política y la planificación urbanística, como veremos a continuación.

\subsection{Proyectos urbanos y gentrificación}

En Valencia, el primer Plan General de Ordenación Urbana de la democracia se aprobó en 1988. Su objetivo era abordar los problemas más importantes del desarrollo urbano después de décadas de incertidumbre y de modificaciones parciales del plan anterior, de 1966. Desde entonces y hasta la actualidad, con este plan vigente y sometido a múltiples cambios parciales que respondían a intereses diversos, se han realizado una serie de intervenciones que han modificado la estructura física y social de la ciudad de Valencia, y que respondían en su mayoría a una estrategia de promoción turística de la ciudad (Salom et al., 2019). Entre ellas, destacan el jardín del Túria, el paseo Marítim, la rehabilitación del centro histórico, el parque de Capçalera, las nuevas avenidas periféricas, como la avenida de França, el bulevard Sud y la avenida de Els 
Figura 5. Plazas de Airbnb por 1.000 hab. (sección censal) en 2018

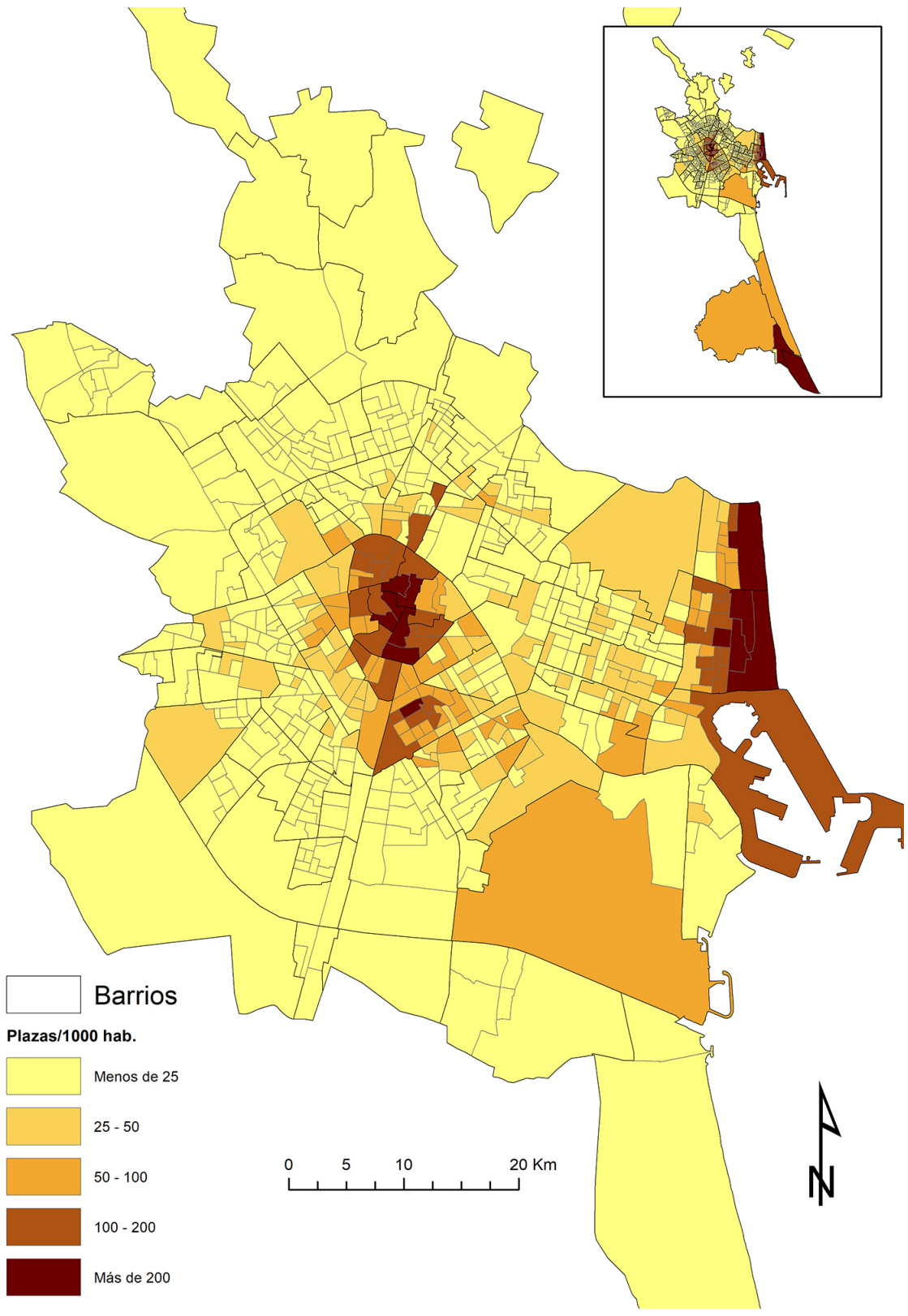

Fuente: Datahippo, elaboración propia. 
Figura 6. Plazas de Airbnb por hectárea (sección censal) en 2018

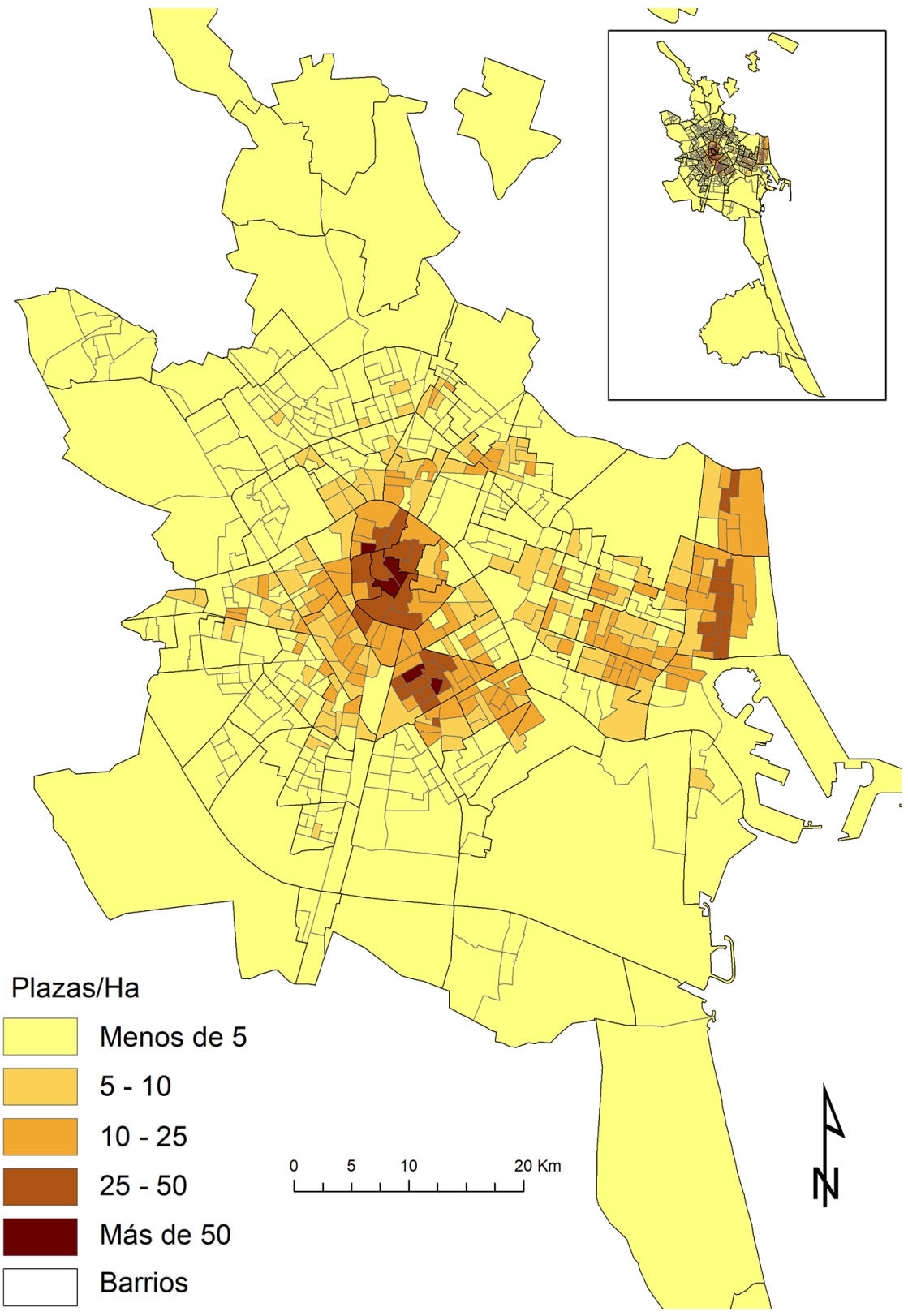

Fuente: Datahippo, elaboración propia. 
Tabla 1. Movimientos de población en el municipio de Valencia en el periodo 2014-2017

\begin{tabular}{lrr}
\hline Tipo de movimiento & Total periodo & Media anual \\
\hline Altas por inmigración y otros motivos & 152.065 & $38.016,3$ \\
Altas por nacimiento & 24.887 & $6.221,8$ \\
Total altas & 176.952 & $44.238,0$ \\
Bajas por emigración y otros motivos & 136.514 & $34.128,5$ \\
Bajas por defunción & 28.001 & $7.000,3$ \\
Total bajas & 164.515 & $41.128,8$ \\
Saldo migratorio (altas-bajas) & 15.551 & $3.887,8$ \\
Saldo vegetativo (nacimientos-defunciones) & -3.114 & $-778,5$ \\
Saldo total & 12.437 & $3.109,3$ \\
Cambios de domicilio dentro de la misma sección & 16.527 & $4.131,8$ \\
Cambios de domicilio entre secciones & 143.934 & $35.983,5$ \\
Total cambios de domicilio & 160.461 & $40.115,25$ \\
\hline
\end{tabular}

Fuente: Ayuntamiento de Valencia. Microdatos de variaciones residenciales, varios años.

Tarongers (con el nuevo campus universitario), el parque Central, Sociòpolis, la Zona d'Activitats Logístiques del Port (ZAL), equipamientos culturales como el IVAM (museo de arte contemporáneo), el Palau de la Música, el Palau de Congressos, infraestructuras de comunicación como la red de MetroValencia (metro y tranvía), entre otras.

En 1989 se inició la planificación de un complejo científico-cultural que se denominó Ciutat de les Arts i les Ciències (CAC), localizado en el viejo cauce del río Turia, en una zona de antigua industrialización cercana al puerto. Este macroproyecto enlazaba con la idea esbozada en el PGOU de rehabilitar el frente marítimo y estrechar la conexión de la ciudad central con el mar. La CAC ocupa más de 350 mil metros cuadrados, recibe al año más de 2,5 millones de visitas y se ha convertido en la imagen icónica de la ciudad, todo ello a pesar de los casos de fraude y de sobrecoste que ha acumulado (más de 625 millones de euros). En paralelo a la construcción de la CAC, se desarrolló el Plan de Actuación Urbanística (PAU) de la avenida de França, que comenzó a ejecutarse a mediados de los noventa del siglo pasado y dio lugar a la aparición de un barrio nuevo: Penya-roja. Este barrio fue construido sobre antiguos terrenos de huerta y almacenes industriales, y se caracteriza por una estructura social de familias jóvenes con nivel de renta medio y alto, en contraposición a los barrios vecinos, con una población mucho más envejecida y mayoritariamente de renta baja.

Una situación similar experimentó otro espacio de la ciudad, la salida hacia Ademuz, al norte, alrededor de otro icono arquitectónico: el Palau de Congressos. En ambos casos, el proceso de gentrificación por nueva construcción no ha supuesto una sustitución de población, pero sí una diferenciación clara de sus vecinos, de clase social mucho más modesta, así como un impulso claro por parte de la política local que ha facilitado, mediante los instrumentos urbanísticos necesarios, la revalorización de estos espacios. 
La organización de grandes eventos, como la Americas' Cup (2007 y 2010) o el Gran Premio de Europa de Fórmula 1 que se celebró en Valencia entre 2008 y 2012, tampoco exentos de polémica y corrupción, supuso modificaciones en el puerto y sus alrededores, lo que ejemplificó, a finales de la década pasada, el llamado urbanismo de contenedores, producto de una política neoliberal que daba prioridad a la imagen de la ciudad hacia el exterior y al llamado «entrepreneurial urbanism» (Swyngedouw et al., 2002). Precisamente, lindando con la Marina, lugar de celebración de estos eventos, se encuentra el barrio del Cabanyal-Canyamelar, uno de los más emblemáticos de la ciudad, por sus características particulares. Se trata de uno de los barrios más directamente afectados por la política de grandes eventos de la ciudad. El Cabanyal-Canyamelar acoge en la actualidad espacios socialmente diferenciados precisamente como consecuencia de esta política: espacios gentrificados por la llegada de nuevos residentes con elevado poder adquisitivo que han contribuido a lo que Montaner y Muxí (2011) denominan «borrado de la memoria», y espacios claramente degradados. Estos últimos coinciden con el proyecto del Ayuntamiento de Valencia de prolongar la avenida de Blasco Ibáñez para hacerla llegar hasta el mar, partiendo el entramado urbano del barrio en dos mitades y rompiendo la trama urbana característica — calles estrechas paralelas a la línea del mar-, lo cual ha generado controversia entre los vecinos y ha originado actitudes a favor y en contra con los consiguientes conflictos (Santamarina Campos, 2014).

Por último, cabe destacar el papel urbanístico de dos parques de nueva construcción en la ciudad. El parque de Capçalera —según Gaja (1996), la única operación en el PGOU de 1988 no ligada directamente con la expansión de la ciudad hacia el mar- es un parque metropolitano con más de 160.000 metros cuadrados que recrea el paisaje original del río. Por otra parte, el parque Central está diseñado para recuperar los terrenos ocupados por las vías del tren que llega hasta la estación del Norte (situada al sur, en pleno centro de la ciudad). Cuando esté finalizado, se recuperará un espacio de grandes dimensiones que servirá para unir los barrios de Russafa y Malilla, históricamente divididos por las vías.

En 2016 se inició el proceso de revisión del PGOU de 1988. El nuevo plan, todavía no aprobado, tiene como objetivo declarado «conseguir una ciudad más habitable para sus ciudadanos» ${ }^{10} \mathrm{y}$ dos argumentos para definir el modelo de ciudad: no incrementar la ocupación de suelo y mejorar la calidad urbana del suelo consolidado.

\section{La movilidad residencial reciente en la ciudad de Valencia}

\subsection{Movilidad residencial y recualificación demográfica}

Los procesos de cambio económico descritos en el apartado anterior están reconfigurando el espacio metropolitano a través de distintos mecanismos, y

10. Ayuntamiento de Valencia: <http://www.valencia.es/revisionplan/es/contenidos/presentacion>. 
uno de los principales es la movilidad residencial de la población. La tabla 1 presenta el resumen de los diferentes tipos de movimientos realizados en el municipio en el periodo 2014-2017, así como los saldos para el conjunto del periodo.

Si dejamos aparte el crecimiento vegetativo, que tiene escaso peso en la dinámica demográfica urbana, los movimientos poblacionales en la ciudad de Valencia en este periodo se reparten prácticamente a partes iguales entre altas (por inmigración o por otros motivos), bajas (por emigración o por otros motivos) y cambios de domicilio. Estos últimos suponen habitualmente un cambio de sección censal, ya que solo una pequeña parte (el 10,3\%) se produce en el interior de la propia sección. A lo largo del periodo estudiado, puede detectarse una tendencia al incremento de la capacidad de atracción de la ciudad, lo que se traduce en un aumento del saldo positivo anual, resultado de la recuperación económica tras el fuerte impacto de la crisis de 2008, que supuso una ruptura en las dinámicas inmigratorias y la salida de gran parte de la población extranjera afincada en la ciudad.

El periodo analizado se caracteriza por un crecimiento demográfico suave, debido a un saldo vegetativo crecientemente negativo, y un saldo migratorio crecientemente positivo. Tal y como puede verse en la tabla 2 , este saldo migratorio positivo se debe sobre todo a la entrada de población extranjera, en particular nacionales de países no comunitarios.

Tabla 2. Número de desplazamientos de entrada y salida al municipio de Valencia según las características de la persona que se desplaza (2014-2017)

\begin{tabular}{|c|c|c|c|c|c|c|c|c|}
\hline \multirow[b]{2}{*}{$\begin{array}{l}\text { Número de } \\
\text { movimientos }\end{array}$} & \multicolumn{2}{|c|}{ Altas } & \multicolumn{2}{|c|}{ Bajas } & \multicolumn{2}{|c|}{ Saldo (altas-bajas) } & \multirow[b]{2}{*}{$\begin{array}{l}\text { Población } \\
2016\end{array}$} & \multirow{2}{*}{$\begin{array}{c}\text { Tasa } \\
\text { periodo } \\
(\%)\end{array}$} \\
\hline & $\begin{array}{c}\text { Total } \\
\text { periodo }\end{array}$ & $\begin{array}{l}\text { Media } \\
\text { anual }\end{array}$ & $\begin{array}{c}\text { Total } \\
\text { periodo }\end{array}$ & $\begin{array}{l}\text { Media } \\
\text { anual }\end{array}$ & $\begin{array}{c}\text { Total } \\
\text { periodo }\end{array}$ & $\begin{array}{l}\text { Media } \\
\text { anual }\end{array}$ & & \\
\hline Españoles & 80.919 & $20.229,75$ & 81.925 & $20.481,25$ & -1.006 & $-251,5$ & 694.551 & $-0,14$ \\
\hline Menor de 18 años & 14.831 & $3.707,75$ & 15.191 & $3.797,75$ & -360 & -90 & 160.482 & $-0,22$ \\
\hline Inferior a bachiller & 28.602 & $7.150,5$ & 32.639 & $8.159,75$ & -4.037 & $-1.009,25$ & 270.249 & $-1,49$ \\
\hline Bachiller y más & 37.486 & $9.371,5$ & 34.095 & $8.523,75$ & 3.391 & 847,75 & 263.820 & 1,29 \\
\hline Unión Europea (28) & 19.163 & $4.790,75$ & 14.911 & $3.727,75$ & 4.252 & 1.063 & 32.870 & 12,94 \\
\hline Menor de 18 años & 2.568 & 642 & 1.949 & 487,25 & 619 & 154,75 & 7.700 & 8,04 \\
\hline Inferior a bachiller & 6.389 & $15.97,25$ & 7.467 & $1.866,75$ & -1.078 & $-269,5$ & 12.971 & $-8,31$ \\
\hline Bachiller y más & 10.206 & $2.551,5$ & 5.495 & $1.373,75$ & 4.711 & $1.177,75$ & 12.199 & 38,62 \\
\hline Fuera de la UE & 51.645 & $12.911,25$ & 39.678 & $9.919,5$ & 11.967 & $2.991,75$ & 64.211 & 18,64 \\
\hline Menor de 18 años & 8.234 & $2.058,5$ & 4.868 & 1.217 & 3.366 & 841,5 & 16.229 & 20,74 \\
\hline Inferior a bachiller & 25.152 & 6.288 & 24.062 & $6.015,5$ & 1.090 & 272,5 & 33.609 & 3,24 \\
\hline Bachiller y más & 18.259 & $4.564,75$ & 10.748 & 2.687 & 7.511 & $1.877,75$ & 14.373 & 52,26 \\
\hline Total & 151.727 & $37.931,75$ & 136.514 & $34.128,5$ & 15.213 & $3.803,25$ & 791.632 & 1,92 \\
\hline Menor de 18 años & 25.633 & $6.408,25$ & 22.008 & 5.502 & 3.625 & 906,25 & 184.411 & 1,97 \\
\hline Inferior a bachiller & 60.143 & $15.035,75$ & 64.168 & 16.042 & -4.025 & $-1.006,25$ & 316.829 & $-1,27$ \\
\hline Bachiller y más & 65.951 & $16.487,75$ & 50.338 & $12.584,5$ & 15.613 & $3.903,25$ & 290.392 & 5,38 \\
\hline
\end{tabular}

Fuente: Microdatos de variaciones residenciales, Servicio de Estadística del Ayuntamiento de Valencia. 
Tabla 3. Cambios de residencia en el interior del municipio de Valencia por nacionalidad y nivel educativo durante el periodo 2014-2017

\begin{tabular}{|c|c|c|c|c|c|c|c|}
\hline \multirow[b]{2}{*}{$\begin{array}{l}\text { Nacionalidad/ nivel } \\
\text { educativo }\end{array}$} & \multicolumn{2}{|c|}{$\begin{array}{c}\text { Dentro de la } \\
\text { sección censal }\end{array}$} & \multicolumn{2}{|c|}{$\begin{array}{l}\text { Entre secciones } \\
\text { censales }\end{array}$} & \multicolumn{3}{|c|}{ Totales } \\
\hline & $\begin{array}{c}\text { Total } \\
\text { periodo }\end{array}$ & $\begin{array}{l}\text { Media } \\
\text { anual }\end{array}$ & $\begin{array}{c}\text { Total } \\
\text { periodo }\end{array}$ & $\begin{array}{l}\text { Media } \\
\text { anual }\end{array}$ & $\begin{array}{l}\text { Total } \\
\text { periodo }\end{array}$ & $\begin{array}{l}\text { Media } \\
\text { anual }\end{array}$ & Tasa (\%) \\
\hline Españoles & 11.139 & $2.784,75$ & 95.036 & 23.759 & 106.175 & $26.543,75$ & 15,29 \\
\hline Menor de 18 años & 2.764 & 691 & 21.938 & $5.484,5$ & 24.702 & $6.175,5$ & 15,39 \\
\hline Inferior a bachiller & 4.424 & 1.106 & 37.429 & $9.357,25$ & 41.853 & $10.463,25$ & 15,49 \\
\hline Bachiller y más & 3.951 & 987,75 & 35.669 & $8.917,25$ & 39.620 & 9.905 & 15,02 \\
\hline Unión Europea (28) & 1.167 & 291,75 & 9.364 & 2.341 & 10.531 & $2.632,75$ & 32,04 \\
\hline Menor de 18 años & 278 & 69,5 & 1.560 & 390 & 1.838 & 459,5 & 23,87 \\
\hline Inferior a bachiller & 524 & 131 & 3.863 & 965,75 & 4.387 & $1.096,75$ & 33,82 \\
\hline Bachiller y más & 365 & 91,25 & 3.941 & 985,25 & 4.306 & $1.076,5$ & 35,30 \\
\hline Fuera de la UE & 4.221 & $1.055,25$ & 39.534 & $9.883,5$ & 43.755 & $10.938,75$ & 68,14 \\
\hline Menor de 18 años & 827 & 206,75 & 6.228 & 1.557 & 7.055 & $1.763,75$ & 43,47 \\
\hline Inferior a bachiller & 2.552 & 638 & 23.841 & $5.960,25$ & 26.393 & $6.598,25$ & 78,53 \\
\hline Bachiller y más & 842 & 210,5 & 9.465 & $2.366,25$ & 10.307 & $2.576,75$ & 71,71 \\
\hline Total & 16.527 & $4.131,75$ & 143.934 & $35.983,5$ & 160.461 & $40.115,25$ & 20,27 \\
\hline Menor de 18 años & 3.869 & 967,25 & 29.726 & $7.431,5$ & 33.595 & $8.398,75$ & 18,22 \\
\hline Inferior a bachiller & 7.500 & 1875 & 65.133 & $16.283,25$ & 72.633 & $18.158,25$ & 22,92 \\
\hline Bachiller y más & 5.158 & $1.289,5$ & 49.075 & $12.268,75$ & 54.233 & $13.558,25$ & 18,68 \\
\hline
\end{tabular}

Fuente: Microdatos de variaciones residenciales, Servicio de Estadística del Ayuntamiento de Valencia. Elaboración propia.

Esta dinámica de entradas-salidas de población se salda con una recualificación de la población residente, ya que, independientemente de la nacionalidad, la población de mayor nivel educativo exhibe un saldo neto positivo, mientras que el saldo migratorio neto de la población con menor nivel educativo es negativo (tabla 2). Cuantitativamente, destaca la tasa migratoria de extranjeros con alto nivel educativo procedentes de países de fuera de la Unión Europea, que supone la entrada neta de más de 7.500 personas, pero también es significativa la entrada neta de población española y de países de la UE con niveles educativos superiores (3.391 y 4.711 respectivamente). Nos encontramos, pues, con un fenómeno de revitalización y recualificación demográfica del municipio de Valencia que se corresponde con las dinámicas de revalorización de las áreas centrales metropolitanas que comentamos en páginas anteriores.

Por otra parte, la distribución por grupos sociodemográficos de los movimientos residenciales internos (entre secciones o en el interior de la sección) nos muestra una gran movilidad residencial. Se producen más de $40.000 \mathrm{cam}$ bios de residencia anuales en el periodo estudiado, lo que supone una tasa de movilidad de la población del 20,3\%; es decir, uno de cada cinco habitantes de la ciudad ha realizado un cambio de residencia a lo largo de estos cinco años. La mayor parte de estos cambios corresponden a los realizados por la población española (26.543 desplazamientos anuales), aunque la tasa de movilidad, o 
sea, el número de desplazamientos por persona, es mayor entre la población extranjera, en particular los nacionales de países no europeos. Por niveles educativos, la tasa de movilidad de la población con menor nivel educativo es mayor que la de la población más educada, pero esto es debido principalmente al elevado número de cambios residenciales de los nacionales de fuera de la Unión Europea.

El patrón territorial de estos movimientos residenciales supone la conformación de zonas atractivas, que muestran tasas migratorias netas positivas, y zonas en vaciamiento demográfico, con salida neta de población. Las primeras se ubican en el centro de la ciudad (distrito de Ciutat Vella y barrios próximos), así como en algunos barrios periféricos. Por el contrario, las principales zonas con tasas negativas son los barrios de Poblados Marítimos, Russafa-En CortsMont Olivet, La Torre-Camí Reial-Malilla, distrito de Benimaclet y Oeste de Benicalap (ver figura 7).

Sin embargo, este patrón espacial que considera la movilidad residencial en conjunto - esto es, los movimientos residenciales internos del municipio y los que proceden o tienen como destino otros municipios- no es estadísticamente significativo ${ }^{11}$, debido a que en el área existen diferentes procesos espaciales contrapuestos o que funcionan a distintas escalas espaciales (Allen, 2011). Mientras que las tasas de migración externa (es decir, las calculadas sobre la base del saldo entre entradas y salidas a la ciudad) muestran un patrón centroperiferia muy marcado, los cambios residenciales en el interior urbano ofrecen un modelo territorial inverso: pérdidas netas de población en el interior de la ciudad en beneficio de los barrios periféricos, tal y como indican los resultados del Hot-Spot Analysis (ver figuras 8 y 9).

Nos encontramos, pues, con una dinámica demográfica que combina la atracción de población externa al municipio focalizada en el centro urbano con una tendencia a la descentralización de la población ya residente hacia los barrios periféricos, zonas de nuevo crecimiento con un menor coste de la vivienda. En el siguiente apartado, veremos cómo la combinación de ambos tipos de movimientos se concreta en la formación de núcleos de población con distinto nivel socioeconómico y, en última instancia, en la formación de espacios socialmente segregados.

\subsection{Espacios de cambio sociodemográfico en la ciudad de Valencia}

En este apartado pretendemos identificar los patrones diferenciados de la movilidad de la población según su nivel socioeconómico y delimitar las zonas atractivas y repulsivas para cada grupo de población. Para ello, se ha analizado la movilidad residencial de los dos grupos de población según el

11. El análisis I de Moran no da resultados estadísticamente significativos: no se detecta una distancia óptima y la aplicación de la distancia media $(958 \mathrm{~m})$ tiene como resultado un p-value de 0,202168 , lo que indica que no existe tendencia al agrupamiento y la distribución de los valores es aleatoria. 
Figura 7. Tasa migratoria total por secciones censales en la ciudad de Valencia, 2014-2017

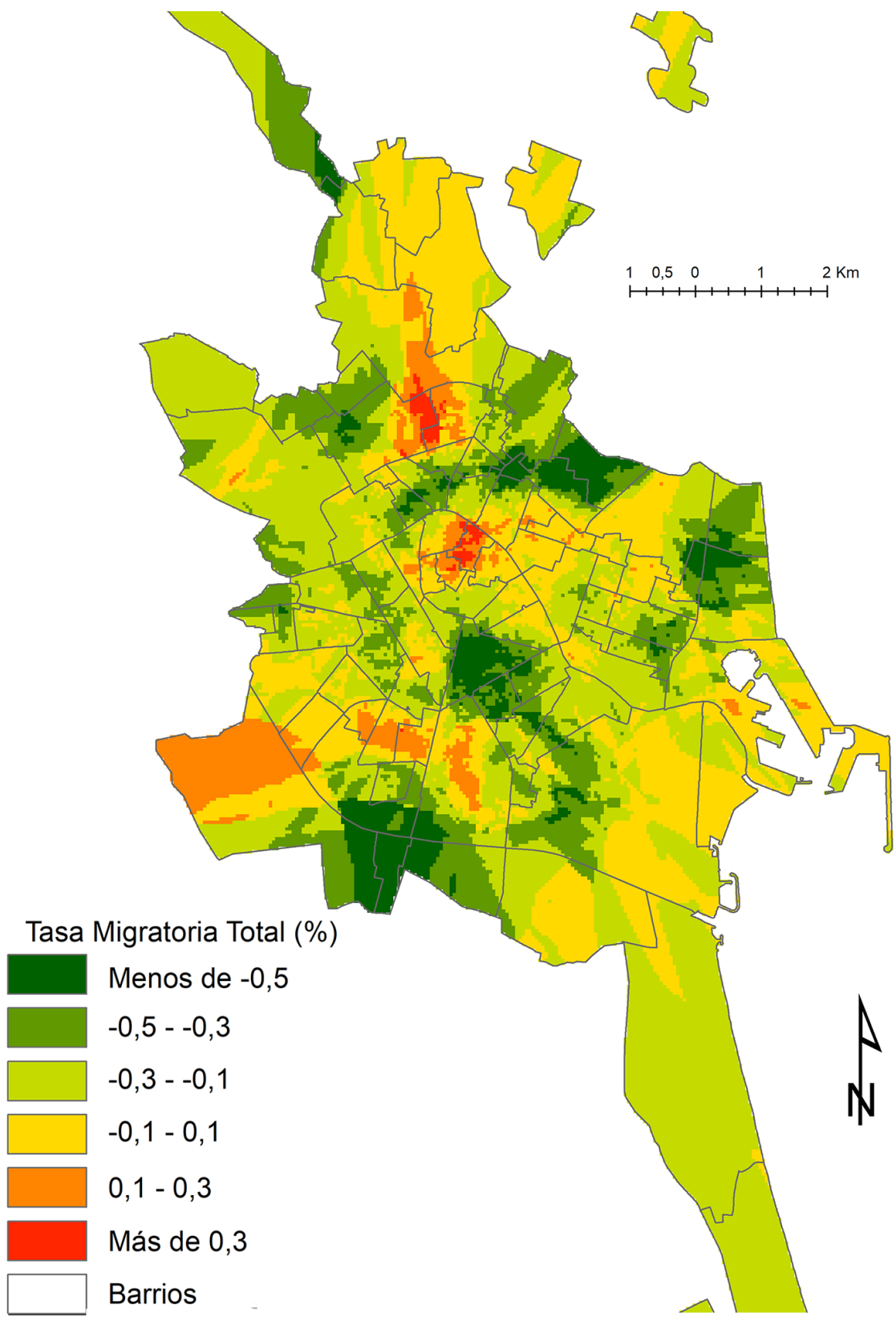

Fuente: Servicio de Estadística del Ayuntamiento de Valencia. Elaboración propia. 
Figura 8. Clústeres significativos de las tasas de cambio residencial por secciones censales en la ciudad de Valencia, 2014-2017

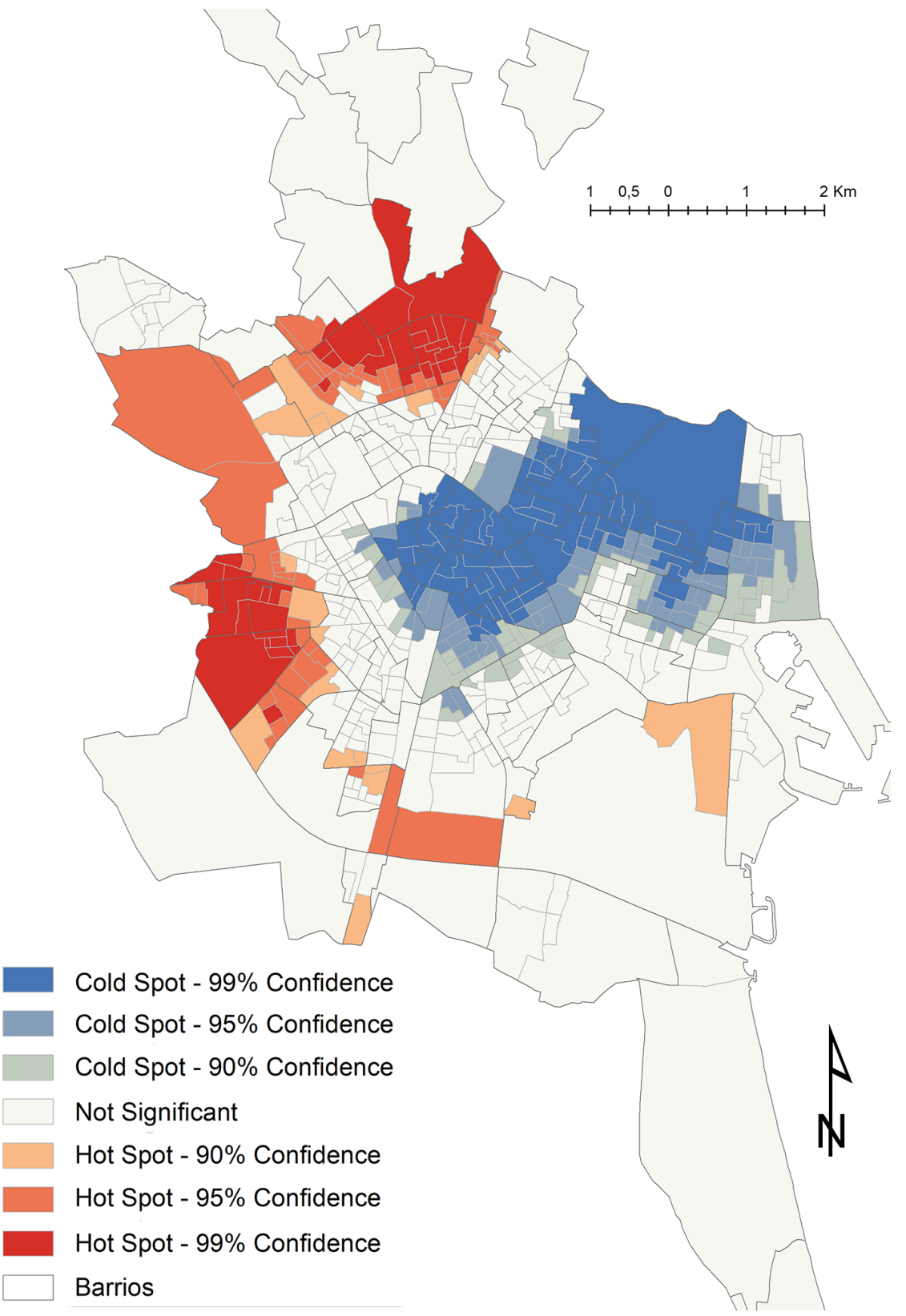

Fuente: Microdatos de variaciones residenciales, Servicio de Estadística del Ayuntamiento de Valencia. Elaboración propia. 
Figura 9. Clústeres significativos de las tasas de migración externa por secciones censales en la ciudad de Valencia, 2014-2017

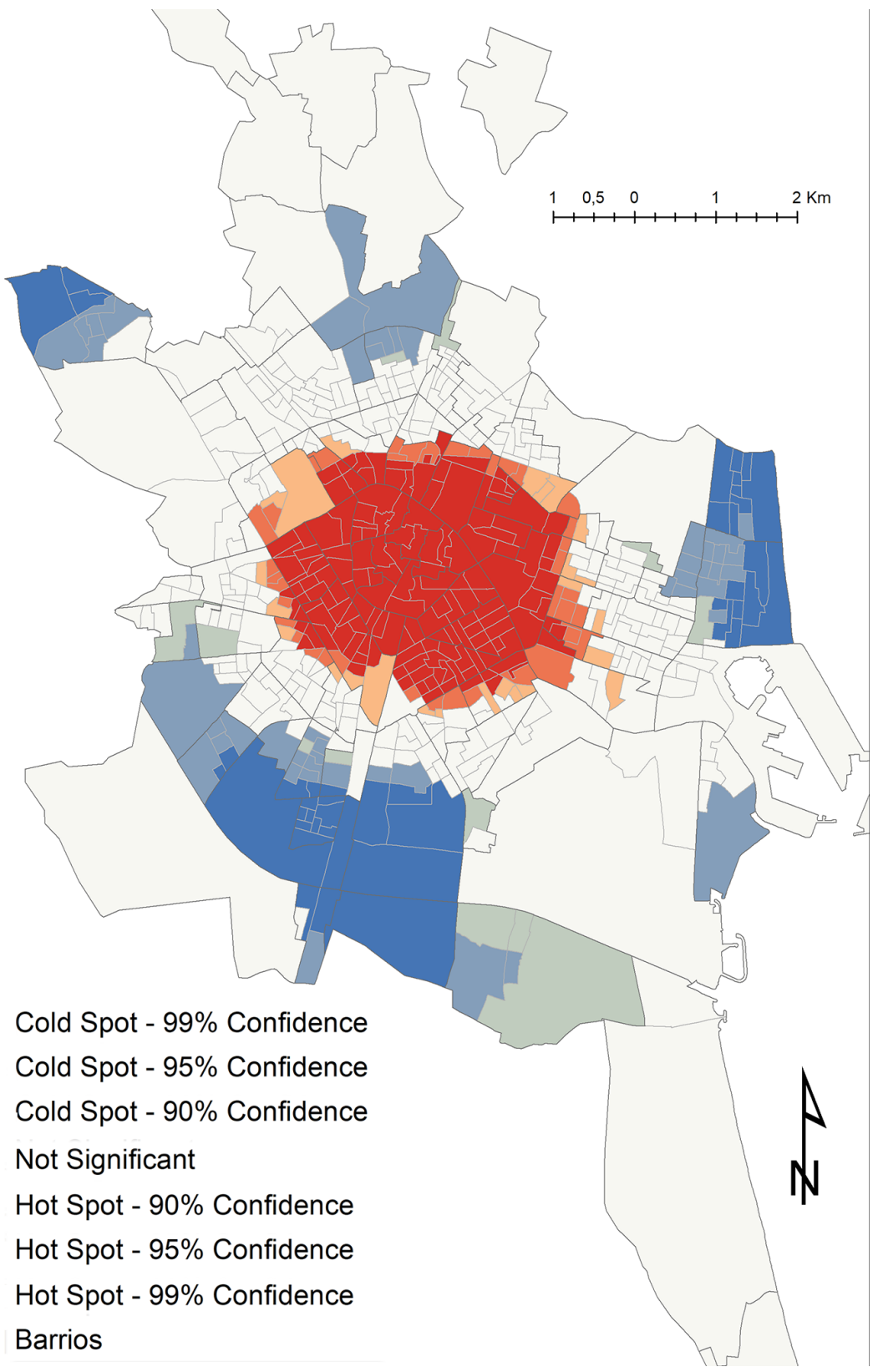

Fuente: Microdatos de variaciones residenciales, Servicio de Estadística del Ayuntamiento de Valencia. Elaboración propia. 
nivel educativo definidos anteriormente, utilizando esta última variable como una aproximación a su nivel socioeconómico. Los resultados indican la existencia de un modelo territorial totalmente contrapuesto: en términos generales, el grupo de población más educada tiende a concentrarse en los distritos centrales de la ciudad, mientras que la de menor nivel educativo presenta en estos mismos distritos las tasas negativas más elevadas, con tendencia a concentrarse en los barrios periféricos del norte y oeste de la ciudad. Este comportamiento no resulta extraño si atendemos al atractivo de la centralidad y accesibilidad y su influencia en el precio del suelo, así como a la dinámica de revalorización de los espacios centrales a que aludimos anteriormente, pero es opuesto al proceso de envejecimiento y abandono del centro histórico ocurrido en etapas anteriores.

A partir del análisis de autocorrelación espacial, hemos identificado los clústeres más significativos en el comportamiento espacial de estos dos grupos de población (figuras 10 y 11). Las áreas donde se concentra el crecimiento de la población con mayor nivel educativo (figura 11) coinciden con las afectadas por los procesos territoriales que señalamos en el apartado anterior. Así, tanto los barrios de Ciutat Vella como el de Cabanyal-Beteró son espacios que están experimentando intensos procesos de turistificación, mientras que los barrios de Ciutat de les Arts i les Ciències y Penya-roja, con su prolongación hacia Camins al Grau, son fruto del proceso de gentrificación generado por el proyecto de la Ciutat de les Arts i les Ciències.

Junto con estas zonas afectadas por procesos más generales, nos encontramos con otras cuya transformación está vinculada a proyectos puntuales o procesos más concretos. Así, el incremento de población educada en el barrio de Faitanar, constituido por una única sección censal, está relacionado con el proyecto urbanístico Sociòpolis ${ }^{12}$. Otros clústeres ubicados en áreas degradadas o con alto nivel de inmigración, como Marxalenes, Orriols, y Natzaret, han sido receptores en los últimos años sea de iniciativas públicas y privadas de renovación de edificios históricos, sea de promociones residenciales en un proceso que ha sido calificado como de new build gentrification ${ }^{13}$.

Por el contrario, las principales zonas de salida neta de población educada son el eje formado por los barrios de Ciutat Universitaria-L'Amistat-La Vega Baixa-L'Illa Perduda, que finaliza en la zona sur del barrio del Cabanyal, espacio coincidente con la zona afectada por la prolongación de la avenida de Blasco Ibáñez, tal y como comentábamos en páginas anteriores, así como algunos núcleos localizados en los distritos periféricos. Por el contrario, las zonas que atraen población de estas características se sitúan al norte y oeste de la ciudad y coinciden con áreas de expansión urbana de nivel económico medio y bajo: Benicalap-Torrefiel-Tormos al norte, y L'Olivereta, Patraix y Faitanar, al sudoeste.

12. Aunque el espacio urbanizado es contiguo al núcleo de poblamiento de La Torre, administrativamente está incluido en el barrio de Faitanar.

13. En palabras del sociólogo Albert Moncusí, entrevistado en Pérez (2015). 
Figura 10. Clústeres significativos de las tasas migratorias totales por secciones censales de la población con nivel educativo de bachiller o más, 2014-2017

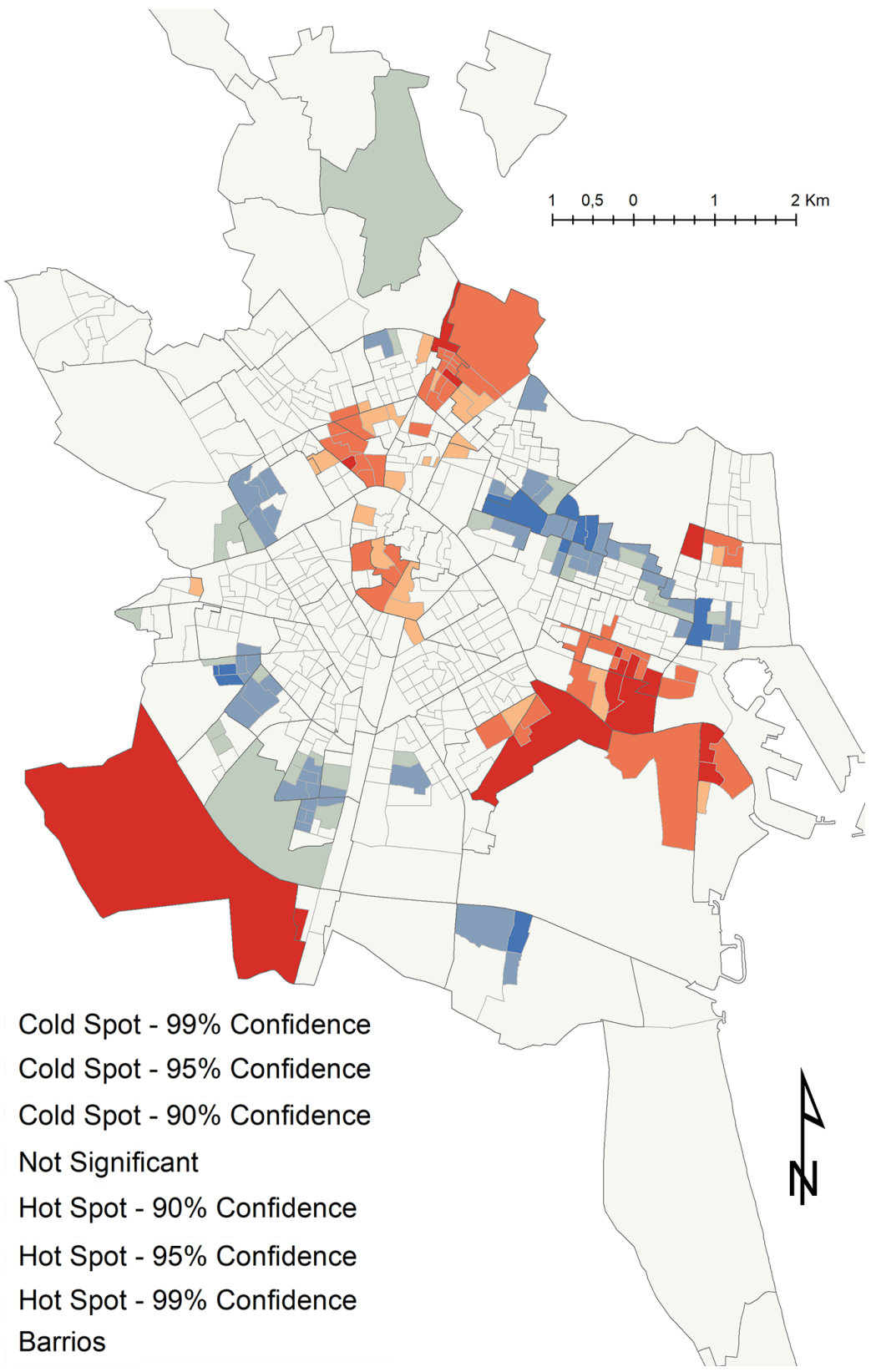

Fuente: Microdatos de variaciones residenciales, Servicio de Estadística del Ayuntamiento de Valencia. Elaboración propia. 
Figura 11. Clústeres significativos de las tasas migratorias totales por secciones censales de la población con nivel educativo inferior a bachiller, 2014-2017

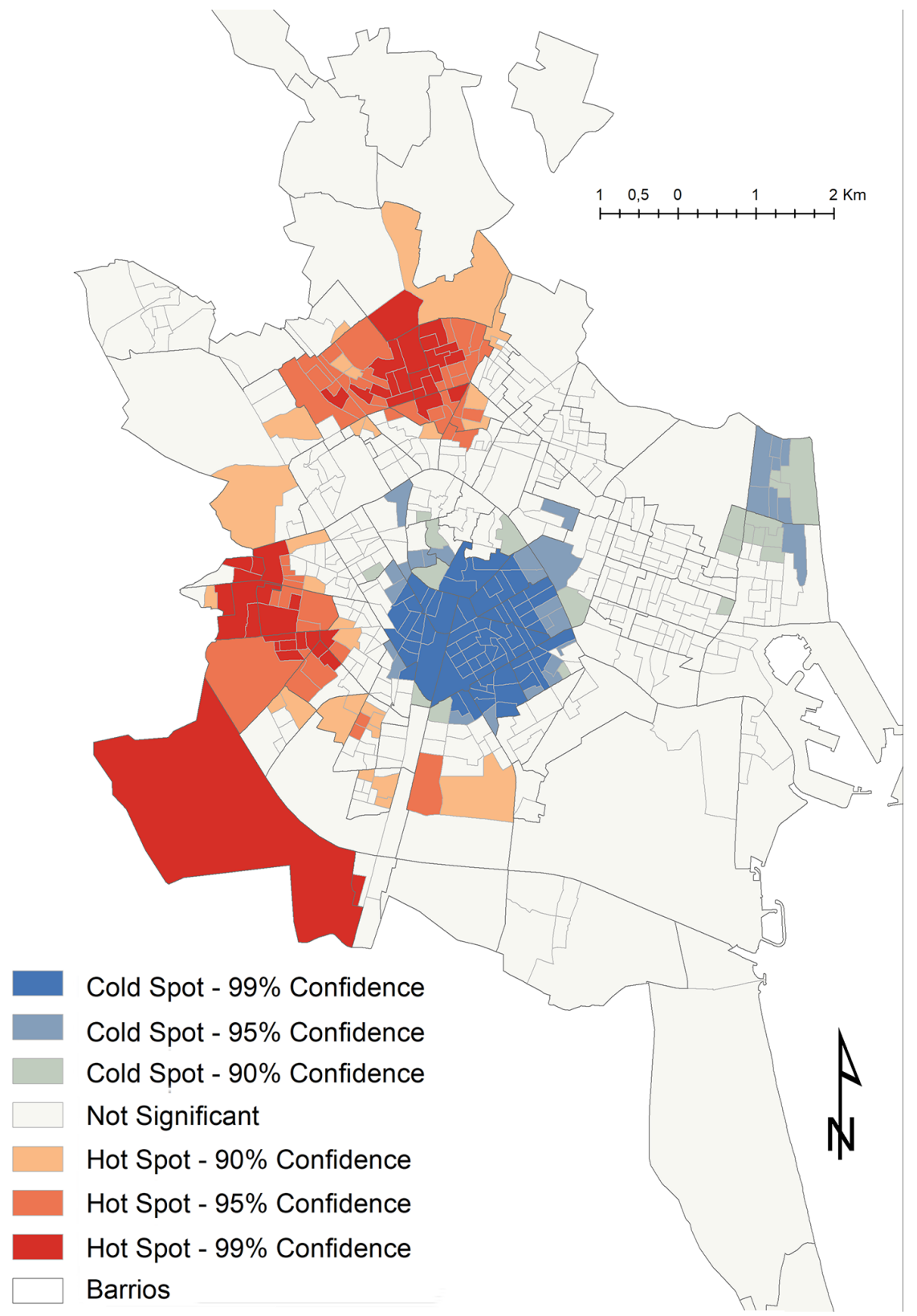

Fuente: Microdatos de variaciones residenciales, Servicio de Estadística del Ayuntamiento de Valencia. Elaboración propia. 


\section{3. ¿Expulsión o mezcla social?}

Las dinámicas gentrificadoras se identifican por definición con la sustitución de la población residente de rentas bajas, que sale del área al no poder afrontar los crecientes precios de la vivienda, por una población con mayor nivel de renta atraída por las calidades físicas y simbólicas de los barrios en proceso de regeneración. Pero no en todos los barrios que están experimentando la entrada de población con mayor nivel educativo se está produciendo este proceso de sustitución, sino que, por el contrario, existen algunas zonas en donde la entrada de población con mayor nivel de renta viene a reforzar una segregación de clases altas ya existentes, y otras en donde la entrada de población de nivel socioeconómico alto contribuye a un mixing social, sin generar la expulsión, al menos por el momento, de la población con menor nivel de renta. Para identificar estos distintos comportamientos, se ha realizado un análisis clúster espacial basado en nueve indicadores de movilidad diferenciada por tipo y nivel educativo de la población, que permiten considerar de forma combinada la movilidad residencial de los dos grupos socioeconómicos principales ${ }^{14}$.

La tipología resultante (figura 12 y tabla 4) nos indica la existencia de cuatro situaciones diferenciadas:

a) Zonas con salida neta de población y sustitución social (gentrificación absoluta). Se trata de zonas con tasas migratorias negativas debido a una salida neta de población con menor nivel educativo insuficientemente compensada por la entrada neta de población con nivel educativo superior, lo que apunta a un claro proceso de gentrificación. En este grupo, nos encontramos, por una parte, con barrios que parten ya de una situación previa favorable, como Jaume Roig (zona 3), el área de La Xerea-Exposició (zona 6) o La Roqueta, ArrancapinsBotanic (zona 9); así como con zonas que incluyen espacios ya gentrificados, junto con barrios próximos que parecen constituir su área de expansión, como es el caso del barrio de Russafa (zona 1), Campanar (zona 12), o la extensa zona compuesta por los barrios de Mestalla-Camins al Grau-Ciutat de les Arts-En Corts-Na Rovella (zona 11), que incluye áreas residenciales burguesas tradicionales junto con nuevos barrios formados a partir de proyectos urbanísticos más recientes, y también como zonas próximas todavía en transformación.

b) Tendencia a la gentrificación, pero con crecimiento demográfico y mezcla social (gentrificación relativa). Este es el caso de los barrios del casco histórico, pertenecientes al distrito de Ciutat Vella, y algunas secciones contiguas: El Pilar, Sant Francesc, La Seu, y Pla del Remei (zonas 2 y 4). Estos barrios tienen saldos netos positivos en los dos grupos educativos considerados, aunque

14. Las variables utilizadas han sido las siguientes: tasa migratoria total, tasa de migración externa, tasa de cambio residencial, tasa migratoria total de la población de mayor nivel educativo, tasa de migración externa de la población de mayor nivel educativo, tasa de cambio residencial de la población de mayor nivel educativo, tasa migratoria total de la población con menor nivel educativo, tasa de migración externa de la población con menor nivel educativo, y tasa de cambio residencial de la población con menor nivel educativo. 
Figura 12. Tipología de áreas según dinámica residencial durante el periodo 2014-2017

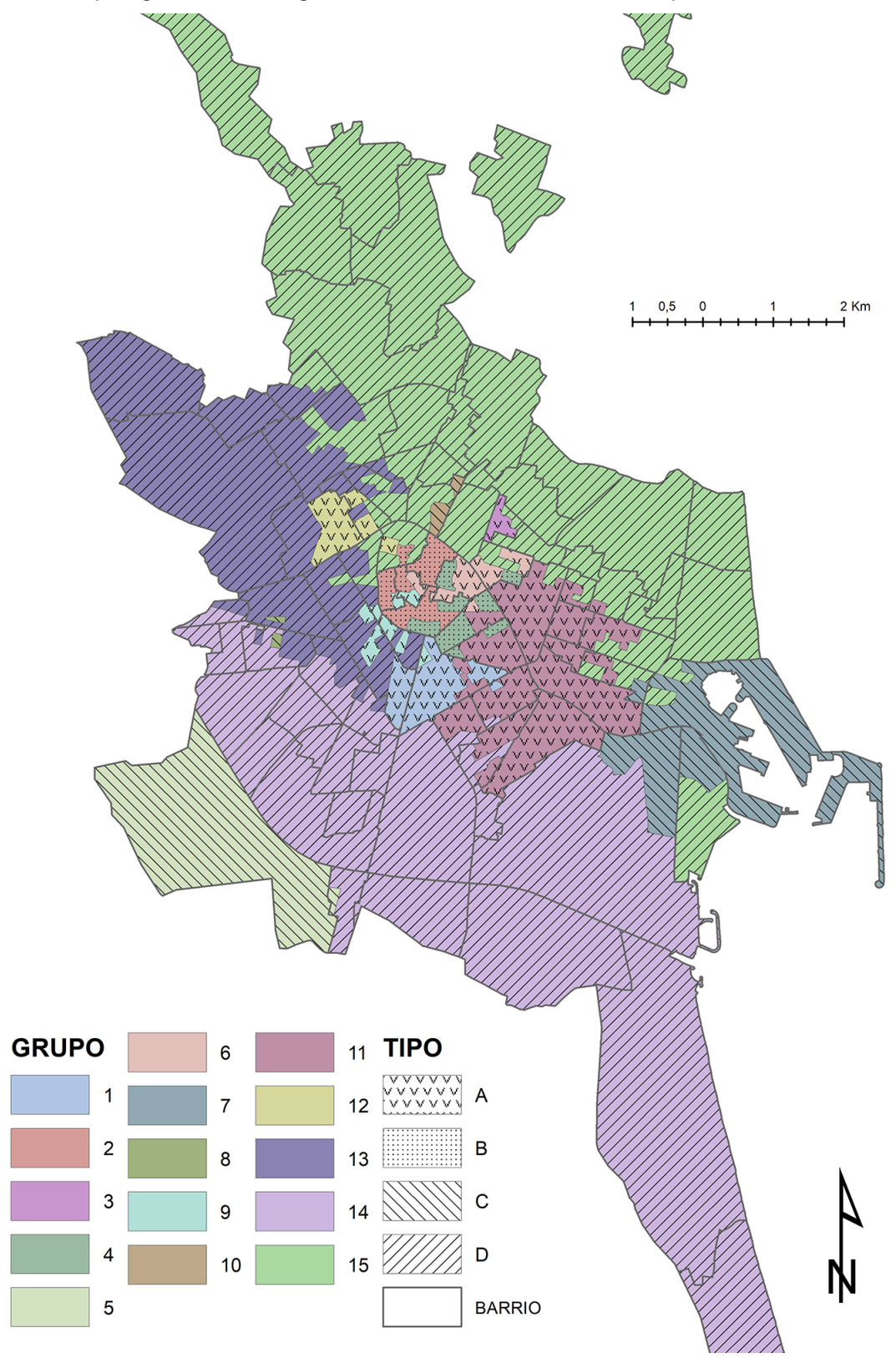

Fuente: Microdatos de variaciones residenciales, Servicio de Estadística del Ayuntamiento de Valencia. Elaboración propia. 
Tabla 4. Zonificación del municipio de Valencia en función de la dinámica migratoria según tipos de movilidad y nivel educativo de la población que se desplaza, 2014-2017

\begin{tabular}{|c|c|c|c|c|c|c|c|c|c|c|c|}
\hline \multirow[b]{3}{*}{ Grupo } & \multirow[b]{3}{*}{ Barrios/distritos } & \multirow[b]{3}{*}{$\begin{array}{l}\text { N. }{ }^{\circ} \\
\text { casos }\end{array}$} & \multicolumn{9}{|c|}{ Variable } \\
\hline & & & \multicolumn{3}{|c|}{ Tasa migratoria total } & \multicolumn{3}{|c|}{ Tasa migración externa } & \multicolumn{3}{|c|}{ Tasa cambio residencial } \\
\hline & & & $\begin{array}{c}\text { Total } \\
\text { población }\end{array}$ & $\begin{array}{c}\text { Población } \\
\text { menor nivel } \\
\text { educativo }\end{array}$ & $\begin{array}{l}\text { Población } \\
\text { mayor nivel } \\
\text { educativo }\end{array}$ & $\begin{array}{c}\text { Total } \\
\text { población }\end{array}$ & $\begin{array}{c}\text { Población } \\
\text { menor nivel } \\
\text { educativo }\end{array}$ & $\begin{array}{l}\text { Población } \\
\text { mayor nivel } \\
\text { educativo }\end{array}$ & $\begin{array}{c}\text { Total } \\
\text { población }\end{array}$ & $\begin{array}{c}\text { Población } \\
\text { menor nivel } \\
\text { educativo }\end{array}$ & $\begin{array}{l}\text { Población } \\
\text { mayor nivel } \\
\text { educativo }\end{array}$ \\
\hline 1 & Russafa & 21 & $-0,67$ & $-9,43$ & 7,16 & 2,02 & $-6,27$ & 6,70 & $-2,08$ & $-5,74$ & 0,46 \\
\hline 2 & $\begin{array}{l}\text { EL Pilar-Sant Francesc- } \\
\text { La Seu }\end{array}$ & 10 & 0,59 & 5,14 & 12,56 & 10,85 & 5,91 & 14,29 & $-0,54$ & 1,08 & $-1,73$ \\
\hline 3 & Jaume Roig & 4 & 0,04 & $-12,75$ & $-3,66$ & $-0,06$ & $-5,18$ & $-1,28$ & $-1,45$ & $-8,13$ & $-2,37$ \\
\hline 4 & $\begin{array}{l}\text { Pla del Remei, } \\
\text { Sant Francesc }\end{array}$ & 10 & 0,12 & 4,74 & 7,19 & 6,80 & 6,40 & 6,70 & 1,02 & 0,24 & 0,49 \\
\hline 5 & Faitanar & 1 & 2,66 & 17,86 & 28,54 & 8,22 & 7,83 & 13,94 & 11,70 & 13,13 & 14,60 \\
\hline 6 & La Xerea-Exposició & 7 & $-0,29$ & $-10,44$ & 4,19 & 3,22 & $-3,00$ & 4,99 & $-2,48$ & $-8,08$ & $-0,80$ \\
\hline 7 & $\begin{array}{l}\text { EL Grau-Norte de } \\
\text { La Punta }\end{array}$ & 9 & $-0,33$ & $-2,87$ & 17,20 & 1,27 & $-2,44$ & 12,95 & 1,61 & 0,47 & 4,25 \\
\hline 8 & Tres Forques-L'Olivereta & 2 & 0,22 & 11,39 & 19,71 & 7,40 & 5,74 & 11,65 & 8,13 & 8,60 & 8,06 \\
\hline 9 & La Roqueta-Arrancapins & 9 & $-0,40$ & $-12,56$ & 9,74 & 5,80 & $-1,94$ & 9,33 & $-2,12$ & $-9,77$ & 0,40 \\
\hline 10 & Morvedre & 1 & 1,67 & 20,54 & 21,41 & 7,57 & 6,91 & 13,78 & 8,26 & 12,09 & 7,62 \\
\hline 11 & $\begin{array}{l}\text { Mestalla-Camins al } \\
\text { Grau-Ciutat de les } \\
\text { Arts-En Corts- } \\
\text { Na Rovella }\end{array}$ & 82 & $-0,29$ & $-3,12$ & 8,14 & 3,03 & $-1,06$ & 7,74 & $-0,25$ & $-1,38$ & 0,40 \\
\hline 12 & Campanar & 4 & $-0,97$ & 11,78 & 10,24 & 6,69 & $-2,54$ & 14,03 & $-5,25$ & $-8,12$ & $-3,79$ \\
\hline 13 & Periferia noroeste & 114 & $-0,16$ & $-0,83$ & 6,30 & 2,12 & $-0,48$ & 5,46 & 0,57 & 0,29 & 0,84 \\
\hline 14 & Periferia suroeste & 114 & $-0,14$ & $-0,34$ & 2,93 & 0,41 & $-0,98$ & 2,55 & 0,75 & 1,05 & 0,38 \\
\hline 15 & Periferia nordeste & 206 & $-0,22$ & $-1,95$ & 4,71 & 1,44 & $-1,11$ & 5,48 & $-0,62$ & $-0,51$ & $-0,77$ \\
\hline Total & & 594 & $-0,20$ & $-1,92$ & 5,77 & 2,01 & $-0,93$ & 5,66 & $-0,08$ & $-0,56$ & 0,10 \\
\hline $\mathrm{R}^{2}$ & & & 0,10 & 0,35 & 0,20 & 0,30 & 0,22 & 0,20 & 0,16 & 0,27 & 0,10 \\
\hline
\end{tabular}

En negrita, valores por encima de la media. $\mathrm{R}^{2}$ refleja la cantidad de variación en los datos originales que se mantiene tras el proceso de agrupamiento, es decir, el peso de esa variable en la discriminación entre las entidades.

Fuente: Microdatos de variaciones residenciales, Servicio de Estadística del Ayuntamiento de Valencia.

la mayor tasa de crecimiento de la población de mayor nivel educativo está provocando una gentrificación relativa. Con relación a la movilidad residencial, funcionan como distribuidores de población respecto al resto de la ciudad: por un lado, reciben población procedente de otros municipios; por otro, aunque en menor medida, pierden población por cambio residencial hacia otros barrios de Valencia.

c) Zonas en crecimiento demográfico, con saldos positivos, de todas las clases sociales. Corresponde a barrios degradados o de antigua inmigración de países no comunitarios que han experimentados procesos puntuales de regeneración o han recibido inversiones para urbanizaciones cerradas: Faitanar (zona 5), 
Morvedre (zona 10) y secciones puntuales en los barrios de Tres ForquesL'Olivereta (zona 8). Aunque con un saldo global negativo, podríamos incluir en este grupo la zona 7, que incluye El Grao, y norte de los barrios de Natzaret y La Punta. En este caso, como en Faitanar, el gran tamaño de las secciones parece enmascarar procesos localizados de gentrificación, por lo que sería necesario complementar el análisis con estudios cualitativos y de mayor detalle.

d) Periferia. Las tres zonas que ocupan la mayor parte del territorio urbano (zonas 13, 14 y 15) tienen en común valores próximos a la media y tasas migratorias totales ligeramente negativas, aunque también presentan algunas diferencias significativas. Así, la zona noroeste (zona 13) es receptora de población con mayor nivel educativo en mayor medida que el resto de la periferia, procedente tanto de otros municipios como del resto de la ciudad, mientras que la zona suroeste (zona 14) es más receptora de población con menor nivel educativo procedente de otras zonas de la ciudad. Finalmente, la zona nordeste (zona 15) es la que presenta unos valores más próximos a la media.

Por tanto, podemos concluir, con todas las reservas adecuadas a una primera aproximación cuantitativa, que, al menos en el caso de la ciudad de Valencia, no siempre la entrada de población con un mayor nivel educativo está provocando una salida neta de la población con menor nivel económico, es decir, un proceso que pudiéramos denominar estrictamente como de gentrificación. Por el contrario, nos encontramos con barrios de la ciudad en donde la entrada de población con mayor nivel socioeconómico conlleva una cierta mezcla social, aunque es posible que esta situación actual se modifique en el futuro, conforme los procesos de transformación socioeconómica se intensifiquen.

\section{Discusión y conclusiones}

La reactivación económica y financiera iniciada en 2013 ha contribuido a la aceleración de algunos procesos socioeconómicos que vienen de la década anterior, y que tienen como consecuencia la revalorización de los espacios urbanos centrales y la atracción de población, española o extranjera, con un mayor nivel de renta, que ha supuesto una recualificación de la población en un proceso común a muchas ciudades españolas (López-Gay et al., 2020). Este proceso no se ha producido por igual en el espacio urbano, lo que ha tenido importantes consecuencias en la movilidad residencial de la población y significado un cambio en las estructuras sociodemográficas urbanas, acelerando las tendencias a la segregación.

El uso de microdatos procedentes del registro municipal de altas y bajas al padrón, junto con herramientas de estadística espacial, proporciona una aproximación cuantitativa a este fenómeno que nos permite identificar y caracterizar los espacios en que se están produciendo estos procesos de forma más acusada. Esta primera aproximación cuantitativa debe sin duda ser complementada con análisis cualitativos, pero nos proporciona una visión general que permite 
medir y comparar de forma homogénea la intensidad de estos fenómenos entre distintos espacios dentro de la misma ciudad, en el tiempo, y entre distintas ciudades.

La aplicación de esta perspectiva de análisis al caso de la ciudad de Valencia ha permitido identificar la tendencia global a la recualificación del centro metropolitano, el contrastado patrón territorial de la movilidad residencial extra e intraurbana, y las diferencias en la movilidad de la población según su nivel socioeconómico. Se han detectado los principales clústeres territoriales en los que se están produciendo procesos de gentrificación, y se han caracterizado en función del tipo de movilidad dominante, los factores que han contribuido a su formación, y las características socioeconómicas preexistentes del espacio en vías de transformación social.

Dando respuesta a las preguntas planteadas en el apartado metodológico, podemos concluir lo siguiente:

- El patrón espacial de los cambios residenciales en la ciudad durante el periodo reciente viene caracterizado por la combinación de la atracción de población externa al municipio con una tendencia a la descentralización de la población ya residente hacia los barrios periféricos, zonas de nuevo crecimiento con un menor coste de la vivienda. Al analizar por separado los cambios residenciales de la población en función de su nivel educativo, encontramos que, mientras que el grupo de población más educada tiende a concentrarse en los distritos centrales de la ciudad, la de menor nivel educativo presenta en estos mismos distritos las tasas negativas más elevadas, con tendencia a concentrarse en los barrios periféricos del norte y oeste de la ciudad. Este comportamiento responde tanto al atractivo de la centralidad y accesibilidad del centro urbano como a la dinámica de revalorización de los espacios centrales, y es opuesto al proceso de envejecimiento y abandono del centro histórico ocurrido en etapas anteriores.

- La metodología aplicada ha permitido identificar varios espacios dentro de la ciudad que muestran una tendencia estadísticamente significativa a la segregación socioeconómica, al haberse convertido en destino preferente de los cambios residenciales de un determinado grupo socioeconómico de población. En algunos de estos espacios, la llegada de nuevos residentes con un perfil específico viene acompañada de la salida de población del tipo opuesto, lo que apunta a la existencia de un proceso de gentrificación. Este es el caso de barrios que parten ya de una especialización en población de alto nivel educativo, como Jaume Roig, el área de La Xerea-Exposició, o La Roqueta, Arrancapins-Botanic, y en los que los movimientos residenciales tienden a agudizar su segregación de clases altas, como de zonas próximas a espacios ya gentrificados que parecen constituir su área de expansión. Este es el caso del barrio de Russafa, Campanar, o el área de Mestalla-Camins al Grau-Ciutat de les Arts.

- Aunque los procesos que están detrás de estas dinámicas son diversos y requieren de un análisis más detallado, parece claro que cambios socioe- 
conómicos, como la expansión del turismo urbano e intervenciones públicas dirigidas a la promoción de la imagen urbana, han contribuido a desencadenar procesos de gentrificación en áreas extensas de la ciudad como el casco antiguo, la fachada marítima, y los barrios próximos al puerto y al complejo de la Ciutat de les Arts i les Ciències, así como a reforzar la segregación socioeconómica en áreas ya históricamente favorecidas. La aproximación cuantitativa realizada nos ha permitido identificar también otros procesos de ámbito territorial más limitado, vinculados a proyectos públicos y privados de renovación urbana, que son susceptibles de un análisis cualitativo detallado. Finalmente, se ha podido constatar la existencia de diversos grados en el proceso de sustitución social en las zonas afectadas, ya que, junto con áreas en donde coincide la entrada de población de mayor nivel educativo con la salida de población de menor nivel socioeconómico en un contexto de salida neta de población, encontramos otras - principalmente el distrito de Ciutat Vella - que siguen siendo atractivas para la población con menor nivel educativo. Se produce, por tanto, una gentrificación relativa que mantiene, al menos por el momento, una situación de mezcla social.

A fecha de hoy, es pronto aún para conocer los efectos que la crisis pandémica tendrá en este patrón territorial y si sus consecuencias sanitarias, económicas y sociales van a modificar la movilidad residencial de forma significativa, de forma que se alteren las tendencias recientes a la segregación socioeconómica urbana. Esto dependerá tanto de la duración del proceso de recuperación económica como del impacto potencial de la crisis sanitaria sobre las preferencias residenciales de los distintos grupos sociales urbanos.

\section{Referencias bibliográficas}

Alexandri, G. y Janoschka, M. (2020). “Post-pandemic” transnational gentrifications: A critical outlook». Urban Studies, 57 (15), 3.202-3.214. <https://doi.org/10.1177/0042098020946453>

Allen, D. W. (2011). GIS tutorial. Spatial Analysis Workbook. Redlands (California): Esri Press.

Amore, A.; Bernardi, C. de y Arvanitis, P. (2020). "The impacts of Airbnb in Athens, Lisbon and Milan: a rent gap theory perspective». Current Issues in Tourism, $1-14$.

Arias Sans, A. (2018). "Turisme i gentrificació: apunts des de Barcelona». Papers, 60, 131-139.

Arias Sans, A. y Quaglieri, A. (2016). «Unravelling airbnb: Urban perspectives from Barcelona». Reinventing the Local in Tourism: Producing, Consuming and Negotiating Place, 73, 209.

Bayona-i-Carrasco, J.; Gil-Alonso, F.; Rubiales-Pérez, M. y Pujadas-Rúbies, I. (2018). «New spatial mobility patterns in large Spanish cities: From the economic boom to the great recession». Applied Spatial Analysis and Policy, 11 (2), 287-312. <https://doi.org/10.1007/s12061-017-9222-x> 
Benach, N. y Albert, A. (2018). «La gentrificación como una estrategia global». Papers: Regió Metropolitana de Barcelona: Territori, Estratègies, Planejament, 60, 17-23.

Cameron, S. (2003). "Gentrification, housing redifferentiation and urban regeneration: "Going for Growth" in Newcastle upon Tyne». Urban Studies, 40 (12), 2.367-2.382. $<$ https://doi.org/10.1080/0042098032000136110>

Checa-Artasu, M. M. (2011). "Gentrificación y cultura: algunas reflexiones». Biblio 3W. Revista Bibliográfica de Geografia y Ciencias Sociales, xvI (94). Recuperado de <http://www.ub.edu/geocrit/b3w-914.htm>.

Cócola-Gant, A. (2018). "Tourism gentrification». En: Lees, L. y Phillips, M. (eds.). Handbook of Gentrification Studies. Cheltenham/Northampton: Edward Elgar Publishing, 281-293.

Cocola-Gant A. y López Gay, A. (2020). "Transnational gentrification, tourism and the formation of "foreign only" enclaves in Barcelona". Urban Studies, 57 (15), 3.025-3.043.

Cucó, J. (2013). «Poniendo a Valencia en el mapa global. Políticas, desarrollos urbanos y narrativas sobre la ciudad». En: Cucó Giner, Josepa (ed.). Metamorfosis urbanas. Ciudades españolas en la dinámica global. Barcelona: Icaria Editorial.

Domínguez, M., Leal, J. y Martínez, E. (2012). "The limits of segregation as an expression of socioeconomic inequality: The Madrid case». En: Maloutas, Thomas y Fujita, Kuniko (eds.). Residential Segregation in Comparative Perspective: Making Sense of Contextual Diversity. Series. Farnham: Ashgate, 217-236.

Donat, C. (2018). «La segregación urbana: marco teórico-conceptual y estado de la cuestión». En: Blanco, A. y Nel-lo, O. (eds.). Barrios y crisis. Crisis económica, segregación urbana e innovación social en Cataluña. Valencia: Tirant lo Blanch. <https://doi.org/10.3280/asur2017-118s10>

Duatis, J.; Buhigas, M. y Cruz, H. (2016). Impacte del lloguer vacacional en el mercat de lloguer residencial de Barcelona. Pla Estratègic de Turisme de Barcelona 2020. Barcelona: Ajuntament de Barcelona.

Easton, S.; Lees, L.; Hubbard, P. y Tate, N. (2020). «Measuring and mapping displacement: The problem of quantification in the battle against gentrification». Urban Studies, 57 (2), 286-306.

EsRi (2020). How Optimized Hot Spot Analysis Works. Recuperado de <https://desktop. arcgis.com/en/arcmap/10.6/tools/spatial-statistics-toolbox/how-optimized-hotspot-analysis-works.htm>.

Florida, R.; Andrés Rodríguez-Pose, A. y Storper, M. (2020). «Cities in a PostCOVID World». Papers in Evolutionary Economic Geography. 14 de septiembre, \# 20.41. Recuperado de <http://econ.geo.uu.nl/peeg/peeg2041.pdf>.

Füller, H. y Michel, B. (2014). «Stop being a tourist! New dynamics of urban tourism in Berlin-Kreuzberg». International Journal of Urban and Regional Research, 38 (4), 1.304-1.318.

Gaja i Diaz, F. (1996). "La transformación de Valencia (I)». Urbanismo: Revista Oficial del Colegio de Arquitectos de Madrid, 29, 78-85.

Gale, D. (1985). «Demographic research on gentrification and displacement». Journal of Planning Literature, 1, 14-29.

Ghaffari, L.; Klein, J. L. y Angulo Baudin, W. (2017). «Toward a socially acceptable gentrification: A review of strategies and practices against displacement». Geography Compass, 12 (2), e12.355. <https://doi.org/10.1111/gec3.12355> 
Glass, R. (1964). «Introduction: aspects of change». En: GLass, R. (ed.). London: aspects of change. Centre for Urban Studies. Londres: MacGibbon and Kee.

Gomà, R. (2018). "La metròpoli entre la gentrificació i el dret a la ciutat». Papers: Regió Metropolitana de Barcelona: Territori, Estratègies, Planejament, 60, 10-14.

Gotнam, K. F. (2005). "Tourism gentrification: The case of New Orleans' vieux carre (French Quarter)». Urban Studies, 42 (7), 1.099-1.121.

Hiernaux, D. y González, C. I. (2014). "Turismo y gentrificación: pistas teóricas sobre una articulación». Revista de Geografía Norte Grande, 58, 55-70.

Horn, K. y Merante, M. (2017). "Is home sharing driving up rents? Evidence from Airbnb in Boston». Journal of Housing Economics, 38, 14-24.

Ilisei, R. y Salom, J. (2018). «Urban Projects and Residential Segregation: A Case Study of the Cabanyal Neighborhood in Valencia (Spain)». Urban Science, 2 (4), 119. <https://doi.org/10.3390/urbansci2040119>

Instituto Nacional de Estadística (2019). Atlas de distribución de renta de los hogares $(A D R H)$. Proyecto técnico. Subdirección General de Estadísticas Sociodemográficas, julio de 2019. Recuperado de <https://www.ine.es/experimental/ atlas/exp_atlas_proyecto.pdf>.

Janoschka, M. (2016). «Gentrificación, desplazamiento, desposesión: procesos urbanos claves en América Latina». Revista Invi, 31 (88), 27-71. <https://doi.org/10.4067/s0718-83582016000300002>

Leal, Jesús y Sorando, Daniel (2016). «Economic Crisis, Social Change and Segregation Processes in Madrid». En: Tammaru, T. et al. (eds.). Socio-economic Segregation in European Capital Cities. Londres: Routledge.

Lees, L.; Shin, H. B. y López-Morales, E. (2016). Planetary gentrification. Londres: John Wiley \& Sons.

Lloyd, C. D. (2010). Spatial Data Analysis. An Introduction for Gis Users. Oxford: Oxford University Press.

López-Gay, A. (2018). "Cambio en la composición social y gentrificación en Barcelona: una mirada a través de los flujos migratorios y residenciales». Papers: Regió Metropolitana de Barcelona: Territori, Estratègies, Planejament, 60, 80-93.

López-Gay, A.; Sales-Favà, J.; Solana, M.; Fernández, A. y Peralta, A. (2019). «Midiendo los procesos de gentrificación en Barcelona y Madrid: una propuesta metodológica». En: XIII CTV 2019 Proceedings: XIII International Conference on Virtual City and Territory. Challenges and paradigms of the contemporary city. UPC, Barcelona, 2-4 de octubre de 2019. Barcelona: CPSV, 8.680. E-ISSN2604-6512. $<$ http://dx.doi.org/10.5821/ctv.8680>

López-Gay, A.; Andújar-Llosa, A. y Salvati, L. (2020). "Residential Mobility, Gentrification and Neighborhood Change in Spanish Cities: A Post-Crisis Perspective». Spatial Demography, 1-28.

López-Morales, E. (2013). «Gentrificación en Chile: aportes conceptuales y evidencias para una discusión necesaria». Revista de Geografía Norte Grande, 56, 31-52. $<$ https://doi.org/10.4067/s0718-34022013000300003>

MÉNDEZ Del VAlle, R. (2019). Ciudades en venta. Estrategias financieras y nuevo ciclo inmobiliario en España. Col. Desarrollo Territorial, 21. Valencia: PUV.

Merrifield, A. (2013). "The urban question under planetary urbanization». International Journal of Urban and Regional Research, 37 (3), 909-922.

Mitchell, D. (2018). «From Boise to Budapest: capital circulation, compound capitalist destruction and the persistence of homelessness». En: Albet, A. y BenACH, N. (eds.). Gentrification as a Global Strategy. Neil Smith and Beyond. Londres: Routledge, 99-111. 
Montaner, J. M. y Muxí, Z. (2011). Arquitectura y política. Barcelona: Ed. Gustavo Gil.

Musterd, S. (2006). «Segregation, urban space and the resurgent city». Urban Studies, 43 (8), 1.325-1.340.

Musterd, Sako; Marcińczak, Szymon; Ham, Maarten van y Tammaru, Tiit (2015). «Socio-economic Segregation in European Capital Cities: Increasing Separation between Poor and Rich». Discussion Paper Series, IZA DP (9.603). Forschungsinstitut zur Zukunft der Arbeit Institute for the Study of Labor. Recuperado de <http:// ftp.iza.org/dp9603.pdf>.

NeL·LO, O. (2018). «Segregació residencial, gentrificació urbana i dret a la ciutat. Una lectura des de Barcelona». Revista Papers, 60, 48-61.

Pérez, Moisés (13 de diciembre de 2015). «Orriols: paradigma del barrio silenciado». elDiario.es. Recuperado de <https://www.eldiario.es/comunitat-valenciana/orriolsparadigma-barrio-silenciado_1_2297696.html>.

Recaño Valverde, J. y Bayona-i-Carrasco, J. (2016). "La movilidad intraurbana en Barcelona y Madrid: un análisis comparativo, en población y territorio de la encrucijada de las ciencias sociales». Actas del XV Congreso de la Población Española. Fuerteventura, 8-10 de junio de 2016. Coord. por Josefina Domínguez Mujica y Ramón Faustino Díaz Hernández, 2016, ISBN 978-849042-258-8, 335-348.

Reuschke, D. y Felstead, A. (2020). "Changing workplace geographies in the COVID-19 crisis». Dialogues in Human Geography, 10 (2), 208-212.

Romero Renau, L. del y Lara Martín, L. (2015). "De barrio-problema a barrio de moda: gentrificación comercial en Russafa, el "Soho" valenciano". Anales de Geografía de la Universidad Complutense, 35 (1), 187-212. <https://doi.org/10.5209/rev_aguc.2015.v35.n1.48969>

Rubiales, M. (2014). «¿Medir la gentrificación? Epistemologías, metodologías y herramientas de investigación de carácter cuantitativo y mixto». Working Papers Series. Contested Cities. Recuperado de <http://contested-cities.net/working-papers/2014/ medir-la-gentrificacion-epistemologias-metodologias-y-herramientas-de-investigacion-de-caracter-cuantitativo-y-mixto/>.

Rubiales, M.; Bayona, J. y Pujadas, I. (2012). «Patrones espaciales de la segregación residencial en la Región Metropolitana de Barcelona. Pautas de segregación de los grupos altos». Scripta Nova, Revista Electrónica de Geografía y Ciencias Sociales, XVI (423). Recuperado de <http://www.ub.edu/geocrit/sn/sn-423.htm>.

- (2013). «Distribución espacial de las clases altas en la región metropolitana de Madrid, 2001-2011». Anales de Geografia de la Universidad Complutense de Madrid, 33 (2), 107-136.

Sabatini, F.; Vásquez, H.; Robles, S. y Rasse, A. (2010). «Gentrificación sin expulsión, fuerza de transformación de las ciudades latinoamericanas: datos e interpretación para Santiago». En: Sabatini, F.; Salcedo, R.; Wormald, G. y Cáceres, G. Tendencias de la segregación en las principales ciudades chilenas. Análisis censal 1982-2002. Santiago de Chile: Instituto Nacional de Estadísticas y Pontificia Universidad Católica de Chile, 165-184. <https://doi.org/10.4067/s0250-71612001008200002>

Salom, J. y Pitarch, M.D. (2017). "Análisis del impacto en el turismo de la estrategia de desarrollo urbano basada en megaproyectos. El caso de la ciudad de Valencia». Cuadernos de Turismo, 40, 573-598. <https://doi.org/10.6018/turismo.40.310111> 
Salom, J. y Fajardo, F. (2017). «Cambios recientes en la estructura territorial sociodemográfica del área metropolitana de Valencia (2001-2011)». Boletín de la Asociación de Geógrafos Españoles, 73. <https://doi.org/10.21138/bage.2412>

Salom, J.; Pitarch, M.D. y Albertos, J.M. (2019). "Desired and undesired effects of the tourism development policy based on megaprojects: the case of Valencia (Spain)». European Journal of Geography, 10 (4), 132-148.

Santamarina, B. (2014). "La ciudad suplantada. Percepciones sobre los nuevos imaginarios (turísticos) de la ciudad de Valencia». PASOS. Revista de Turismo y Patrimonio Cultural, 12 (4), 707-718. <https://doi.org/10.25145/j.pasos.2014.12.051>

Santamarina Campos, B. (2014). «El oficio de la resistencia. Salvem y Viu al Cabanyal como formas de contención del urbanismo neoliberal». Revista de Dialectología y Tradiciones Populares, LXIX (2), 305-326. <https://doi.org/10.3989/rdtp.2014.02.003>

Santamarina, B. y Moncusi, A. (2013). «De huertas y barracas a galaxias faraónicas. Percepciones sociales sobre la mutación de la ciudad de Valencia». Papers. Revista de Sociologia, 98 (2), 365-391. <https://doi.org/10.5565/rev/papers/v98n2.468>

Sassen, S. (1991). The Global City: New York, London, Tokyo. Princeton: Princeton University Press.

Sмith, N. (2002). «New globalism, new urbanism: Gentrification as global urban strategy». Antipode, 34 (3), 434-457. <https://doi.org/10.1111/1467-8330.00249>

Solana, M.; Badía, A.; Cebollada, A.; Ortiz, A. y Vera, A. (2016). Espacios globales y lugares próximos. Barcelona: Icaria.

Sorando, Daniel y Leal, Jesús (2019). «Distantes y desiguales: el declive de la mezcla social en Barcelona y Madrid». Revista Española de Investigaciones Sociológicas, 167, $125-148$. <http://dx.doi. org/10.5477/cis/reis.167.125>

Swyngedouw, E.; Moulaert, F.; Rodriguez, A. (2002). «Neoliberal Urbanization in Europe: Large - Scale Urban Development Projects and the New Urban Policy». Antipode, 34, 542-577. <https://doi.org/10.1111/1467-8330.00254>

Tammaru, Tiit; Marciczak, Szymon y Ham, Maarten van (eds.) (2016). Socio-Economic Segregation in European Capital Cities: East Meets West. Londres: Routledge.

Vallas, S. P. y Kovalainen, A. (2019). «Taking Stock of the Digital Revolution». En: Vallas, S. P. y Kovalainen, A. (ed.). Work and Labor in the Digital Age. Research in the Sociology of Work, 33. Emerald Publishing Limited, 1-12. <https://doi.org/10.1108/s0277-283320190000033001> 